\title{
THE HUMAN VESTIBULAR CORTEX REVEALED BY COORDINATE-BASED ACTIVATION LIKELIHOOD ESTIMATION META-ANALYSIS
}

\author{
C. LOPEZ, ${ }^{\mathrm{a}, \mathrm{b} \dagger *}$ O. BLANKE ${ }^{\mathrm{c}, \mathrm{d}, \mathrm{e}}$ AND F. W. MAST ${ }^{\mathrm{a}}$ \\ ${ }^{a}$ Department of Psychology, University of Bern, Bern, Switzerland \\ ${ }^{\mathrm{b}}$ Laboratoire de Neurosciences Intégratives et Adaptatives, \\ UMR 7260, Centre National de la Recherche Scientifique (CNRS), \\ Aix-Marseille Université, Marseille, France \\ ${ }^{\mathrm{c}}$ Laboratory of Cognitive Neuroscience, School of Life Sciences, \\ Brain Mind Institute, Ecole Polytechnique Fédérale de Lausanne, \\ Lausanne, Switzerland \\ ${ }^{\mathrm{d}}$ Department of Neurology, University Hospital, Geneva, Switzerland \\ ${ }^{\text {e }}$ Center for Neuroprosthetics, School of Life Sciences, \\ Ecole Polytechnique Fédérale de Lausanne, Switzerland
}

\begin{abstract}
The vestibular system contributes to the control of posture and eye movements and is also involved in various cognitive functions including spatial navigation and memory. These functions are subtended by projections to a vestibular cortex, whose exact location in the human brain is still a matter of debate (Lopez and Blanke, 2011). The vestibular cortex can be defined as the network of all cortical areas receiving inputs from the vestibular system, including areas where vestibular signals influence the processing of other sensory (e.g. somatosensory and visual) and motor signals. Previous neuroimaging studies used caloric vestibular stimulation (CVS), galvanic vestibular stimulation (GVS), and auditory stimulation (clicks and short-tone bursts) to activate the vestibular receptors and localize the vestibular cortex. However, these three methods differ regarding the receptors stimulated (otoliths, semicircular canals) and the concurrent activation of the tactile, thermal, nociceptive and auditory systems. To evaluate the convergence between these methods and provide a statistical analysis of the localization of the human vestibular cortex, we performed an activation likelihood estimation (ALE) metaanalysis of neuroimaging studies using CVS, GVS, and auditory stimuli. We analyzed a total of 352 activation foci reported in 16 studies carried out in a total of 192 healthy participants. The results reveal that the main regions activated by CVS, GVS, or auditory stimuli were located in the
\end{abstract}

\footnotetext{
*Correspondence to: C. Lopez, Universität Bern, Institut für Psychologie, Abteilung für Kognitive Psychologie, Wahrnehmung und Methodenlehre, Muesmattstrasse 45, 3012 Bern, Switzerland. Tel: +33-4-13-55-08-41; fax: +33-4-13-55-08-44.

E-mail addresses: christophe.lopez@univ-amu.fr, christophe.g. lopez@gmail.com (C. Lopez).

† Current address: Laboratoire de Neurosciences Intégratives et Adaptatives, UMR 7260, Centre National de la Recherche Scientifique (CNRS), Aix-Marseille Université, Centre St Charles, Pôle 3C, Case B 3, Place Victor Hugo 13331, Marseille Cedex 03, France. Abbreviations: ALE, activation likelihood estimation; CVS, caloric vestibular stimulation; fMRI, functional magnetic resonance imaging; GVS, galvanic vestibular stimulation; MEG, magnetoencephalography; PET, positron emission tomography; PIVC, parieto-insular vestibular cortex.
}

\begin{abstract}
Sylvian fissure, insula, retroinsular cortex, fronto-parietal operculum, superior temporal gyrus, and cingulate cortex. Conjunction analysis indicated that regions showing convergence between two stimulation methods were located in the median (short gyrus III) and posterior (long gyrus IV) insula, parietal operculum and retroinsular cortex (Ri). The only area of convergence between all three methods of stimulation was located in $\mathrm{Ri}$. The data indicate that $\mathrm{Ri}$, parietal operculum and posterior insula are vestibular regions where afferents converge from otoliths and semicircular canals, and may thus be involved in the processing of signals informing about body rotations, translations and tilts. Results from the meta-analysis are in agreement with electrophysiological recordings in monkeys showing main vestibular projections in the transitional zone between $\mathrm{Ri}$, the insular granular field (Ig), and SII. () 2012 IBRO. Published by Elsevier Ltd. All rights reserved.
\end{abstract}

Key words: vestibular system, meta-analysis, caloric vestibular stimulation, galvanic vestibular stimulation, insula, parietal operculum.

\section{INTRODUCTION}

The vestibular system encodes translations and rotations of the head in space and provides the brain with signals about gravity. Vestibular signals are of crucial importance for oculomotor and postural reflexes, and they are also at the basis of conscious perception and spatial cognition (Berthoz, 1996). The large range of functions attributed to the vestibular system is evident from investigations into self-motion perception, spatial navigation and memory (Berthoz et al., 1995; Brandt et al., 2005), perception of the vertical (Lopez et al., 2007), visual processing related to gravitational cues (Indovina et al., 2005; Lopez et al., 2009), and bodily self-consciousness (Blanke et al., 2002). These multiple sensorimotor and cognitive functions are subserved by vestibular pathways originating in the vestibular nuclei in the brainstem to several thalamic nuclei, the cerebellum, and the cerebral cortex.

Based on previous electrophysiological evidence about vestibular-related brain areas in animals, a widely distributed cortical vestibular network has been reported (review in Lopez and Blanke, 2011). This so-called vestibular cortex can be defined as the network encompassing any area of the cortex that receives inputs from the vestibular system. This includes all multisensory areas of the cortex that are influenced by vestibular signals. Data collected in several primate species suggest that the 
so-called parieto-insular vestibular cortex (PIVC), located in the posterior insula/retroinsular cortex and in the upper or lower banks of the lateral sulcus, constitutes the core vestibular cortex (Grüsser et al., 1990, 1994; Guldin and Grüsser, 1998). Yet, in animals, the vestibular cortex also extends to the primary somatosensory cortex, posterior parietal areas (intraparietal sulcus, area MST), frontal cortex (motor and premotor cortex, frontal eye fields), hippocampus and cingulate cortex (Schwarz and Fredrickson, 1971; Grüsser et al., 1994; O'Mara et al., 1994; Guldin and Grüsser, 1998; Bremmer et al., 2002; Ebata et al., 2004; Gu et al., 2007; Liu et al., 2011). In humans, knowledge about the cortical regions involved in vestibular processing is still relatively sparse when compared to the wealth of knowledge ascertained about visual, somatosensory and auditory cortex. Neurological observations in conscious epileptic patients revealed that electrical stimulation of the superior temporal cortex, posterior parietal cortex, somatosensory cortex, and insula may evoke vestibular sensations (Penfield, 1957; Blanke et al., 2000a, 2002; Kahane et al., 2003). These clinical data were extended by neuroimaging studies in which healthy humans were exposed to various techniques of vestibular stimulation. Functional magnetic resonance imaging (fMRI) and positron emission tomography (PET) studies revealed activations in the insula, superior temporal gyrus, inferior parietal lobule, somatosensory cortex, cingulate gyrus, frontal cortex, and hippocampus (Bottini et al., 1994; Vitte et al., 1996; Bucher et al., 1998; Lobel et al., 1998; Bense et al., 2001; Suzuki et al., 2001; Deutschländer et al., 2002; Fasold et al., 2002; Dieterich et al., 2003; Emri et al., 2003; Hegemann et al., 2003; Stephan et al., 2005; Eickhoff et al., 2006b; Marcelli et al., 2009).

It is noteworthy that the exact location of the human ana$\log$ of the PIVC is still controversial (Lopez and Blanke, 2011). Thus, on the basis of clinical observations, it has been suggested that the PIVC is located in the posterior insula (Brandt and Dieterich, 1999), or more superficially in the temporo-peri-Sylvian vestibular cortex (Kahane et al., 2003), whereas recent neuroimaging data suggest the more dorsally located parietal operculum as the core vestibular cortex (Eickhoff et al., 2006b; Zu Eulenburg et al., 2012).

Compared with other sensory modalities, mapping the vestibular cortex in humans is hampered by the fact that vestibular receptors are sensitive to head motion (angular and linear acceleration of the head), and therefore, it is not possible to apply adequate vestibular stimuli while using neuroimaging techniques such as $\mathrm{FMRI}, \mathrm{PET}$ and magnetoencephalography (MEG). For this reason, stimulation techniques other than true motion had to be applied in order to bypass this limitation. The peripheral vestibular apparatus can be stimulated by means of caloric vestibular stimulation (CVS) and galvanic vestibular stimulation (GVS), as well as by means of auditory stimuli (clicks and short-tone bursts). Fig. 1 summarizes the physiological mechanisms by which CVS, GVS and sounds activate the vestibular receptors and co-activate other sensory systems (fore details, see Fig. 1 legend). It is important to note that these three methods differ in terms of (1) the vestibular receptors stimulated (otoliths versus semicircular canals) and thus the nature of the rotational or translational self-motion or self-tilt evoked and (2) the concurrent stimulation of the tactile, nociceptive, thermoreceptive, and auditory systems. This variability renders difficult the direct comparison of the patterns of activation shown in previous neuroimaging studies. While CVS predominantly stimulates the pathways from the horizontal semicircular canals to the cortex (with a weaker contribution of the anterior and posterior canals, Aw et al., 2000) and interacts with the neural processing of gravito-inertial signals (Peterka et al., 2004), sounds mainly activate pathways running from the saccule to the cerebral cortex (with a potential contribution of the semicircular canals (Xu et al., 2009; see Fig. 1 legend for a detailed description). Lastly, GVS provides a vestibular stimulation that involves all vestibular afferents (Fitzpatrick and Day, 2004). The degree to which the cortical responses to these three types of vestibular stimulation overlap remains so far unknown, because no comparative analysis has been carried out to identify differences and commonalities in cerebral activation patterns between the different stimulation methods. Several methods are available to compute a meta-analysis of neuroimaging data, including coordinatebased and image-based meta-analyses, and they have previously been applied successfully to different functional neuroimaging studies (Salimi-Khorshidi et al., 2009; Laird et al., 2009b).

Here, we used a coordinate-based analysis known as activation likelihood estimation (ALE) meta-analysis to localize the human vestibular cortex (Laird et al., 2005; Eickhoff et al., 2009; Laird et al., 2009a). This method provides a statistical description of the overlap between activation foci reported in neuroimaging studies. During the last few years, this method has been applied to identify the motor cortex involved in execution/observation of movements (Caspers et al., 2010), or to identify brain regions involved in audition (Petacchi et al., 2005), trigeminal sensation (Albrecht et al., 2010), olfaction, gustation, interoception, somatosensation, and pain (Kurth et al., 2010b). Recently, the ALE method has been applied to localize the vestibular cortex (Zu Eulenburg et al., 2012), but without identifying the cerebral networks responding differently and similarly to CVS, GVS and sounds. These authors identified the right parietal operculum (area OP2) as "the core region for vestibular processing" and showed that this area is directly connected with all other vestibular regions revealed by the meta-analysis. For the present analysis, we analyzed 352 foci of activation reported in 16 neuroimaging studies. We calculated the brain activations specific to CVS, GVS, and auditory stimulation, and analyzed the spatial overlap between these activations. Because the laterality of the cortical projections have been proposed to differ for vestibular as compared to other sensory systems (Dieterich et al., 2003; Janzen et al., 2008), we also analyzed the laterality and pattern of hemispheric dominance resulting from the activation of the left and right ears separately. The present ALE meta-analysis revealed activations mainly in the bilateral insula, retroinsular cortex, inferior parietal lobule, superior temporal gyrus, the caudal part of the anterior cingulate gyrus, and the precuneus. We discuss these neuroimaging data with respect to electrophysiological and anatomical data from animals as well as clinical data. 
A caloric vestibular stimulation (CVS)

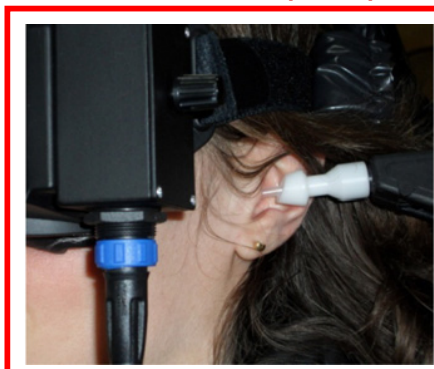

Injection of cold $\left(0,4,10,20^{\circ} \mathrm{C}\right)$ or warm $\left(44^{\circ} \mathrm{C}\right)$ water or gas into the external auditory canal.

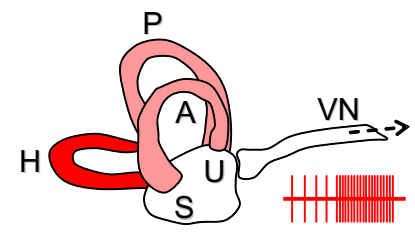

Warm water increases firing rate mainly in the afferents of the horizontal semicircular canals. A weaker contribution of vertical canals and an interaction with the neural processing of otolithic signals have been demonstrated.
B galvanic vestibular stimulation (GVS)

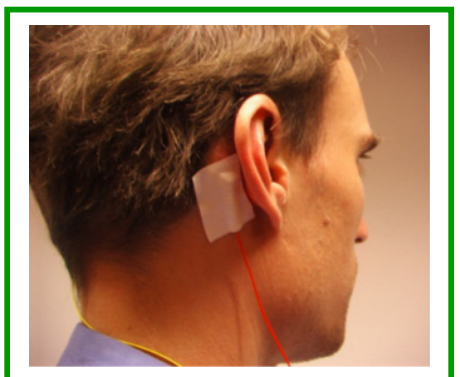

Application of a percutaneous current through an anode and a cathode placed on the opposite mastoid processes.

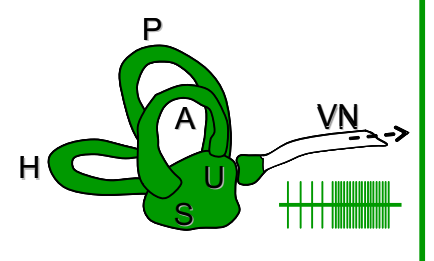

Firing rate increases in the vestibular afferents ipsilateral to the cathode and decreases to the side of the anode.

\section{C sound-induced vestibular stimulation}

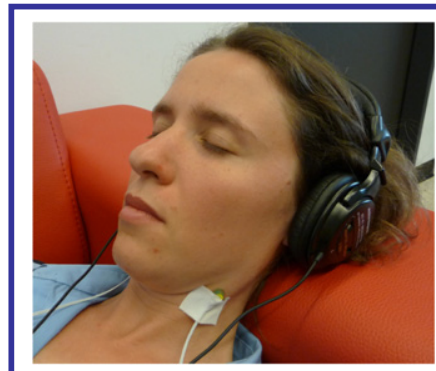

Presentation of $102 \mathrm{~dB}$ clicks $(1 \mathrm{~ms}$ long, at $1 \mathrm{~Hz}$ ) or short tone bursts (10 ms long, $500 \mathrm{~Hz}$, at $3 \mathrm{~Hz}$ ) through headphones.

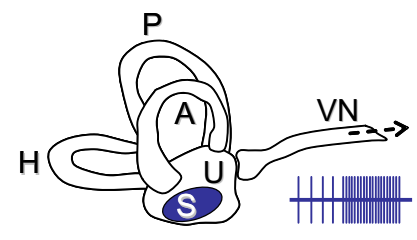

Air-conducted sounds

preferentially activate saccular receptors.

A weaker contribution of other otolithic receptors and

semicircular canals has also been proposed.

Fig. 1. Three main methods to stimulate the vestibular receptors. (A) Caloric vestibular stimulation (CVS) consists of irrigating the external auditory canal with warm or cold water or air-flow (Maes et al., 2007). When thermal energy is transmitted through the temporal bone to the inner ear, a convective flow of the endolymph is created, stimulating the vestibular sensors in the crista ampullaris of the semicircular canals. CVS stimulates mainly the horizontal semicircular canals, although a weak stimulation of the vertical canals has been reported (Aw et al., 2000). In addition, semicircular canals' signals can influence the neural processing of otolithic signals to modify tilt and translation perception (Merfeld et al., 2005). Studies of the caloric nystagmus showed that CVS modifies tilt and translation signals at the oculomotor level (Peterka et al., 2004) and suggest similar influences on the cortico-vestibular projections. CVS evokes a nystagmus and self-motion perception, often leading to vertigo and a sensation of dizziness. Importantly, CVS produces concurrent somatosensory (tactile, thermal and nociceptive) stimulation of the external auditory canal and auditory perception. (B) Galvanic vestibular stimulation (GVS) consists of applying a weak percutaneous current through an anode and a cathode placed over the opposite mastoid processes. GVS modulates the level of hyperpolarization of the vestibular neuroepithelia and the electrical current is thought to "bypass the transduction mechanism of the hair cells" (Fitzpatrick and Day, 2004). Animal data suggest that GVS stimulates the spike trigger zone on the vestibular afferents (Fitzpatrick and Day, 2004), while recent clinical observations suggest a direct influence of GVS on hair cells (Aw et al., 2008). The firing rate increases in the vestibular afferents ipsilateral to the cathode, while it decreases to the side of the anode. Thus, GVS stimulates simultaneously all otoliths and semicircular canals' afferents (Fitzpatrick and Day, 2004). GVS has been associated with tactile, thermal and nociceptive sensations, nausea, vertigo and metallic taste in the mouth. Some neuroimaging studies used an electrical current applied to participant's neck or back in order to control for some of the extravestibular effects (Lobel et al., 1998; Bense et al., 2001). (C) Auditory stimuli such as clicks and short-tone bursts can stimulate the vestibular receptors. Resulting sound-evoked myogenic potentials can be recordable at the level of the sternocleidomastoid muscles (vestibular-evoked myogenic potentials, VEMPs) and extraocular muscles (Halmagyi et al., 2005). Sounds are thought to activate mainly the neural pathways running from the otolith organs (and mainly from the saccular receptors sensing vertical accelerations). However, recent electrophysiological recordings in animals indicate that afferents from both otolith and semicircular canals are activated by sounds (Xu et al., 2009; Zhu et al., 2011). Zhu et al. (2011) showed that clicks activate a majority (81\%) of the afferents from the otoliths and demonstrated that there is also a significant contribution of the canal afferents (43\%). Recently, high-intensity clicks at $120 \mathrm{~dB}$ and short-tone bursts at the frequency of $500 \mathrm{~Hz}(102 \mathrm{~dB}$ during $10 \mathrm{~ms})$ have been used to stimulate vestibular receptors in neuroimaging studies (Miyamoto et al., 2007; Janzen et al., 2008; Schlindwein et al., 2008). Because of concurrent auditory stimulation, these studies used control conditions involving low-intensity clicks (not evoking VEMPs) or white noise (controlling for the loudness of the auditory stimuli). A, H, P: Anterior, Horizontal and Posterior semicircular canals; S: saccule; U: utricule; VN: vestibular nerve.

\section{EXPERIMENTAL PROCEDURES}

\section{Identification and selection of the publications}

Relevant functional neuroimaging studies published before February 2011 were found on Pubmed, ISI Web of Science and Google Scholar using combinations of the keywords "vestibular, cortex, vestibular stimulation, caloric stimulation, galvanic stimulation, sound, VEMPs, human, fMRI, PET, MEG", as well as by reviewing the references of all identified articles. Peerreviewed publications were included in the present ALE metaanalysis on the basis of five criteria:

(1) Use of CVS, GVS, or sounds to stimulate the vestibular system. Various techniques have been applied and we included CVS studies that employed unilateral irrigations of the external auditory canal with cold water (iced water, 
$0^{\circ}, 4^{\circ}, 10^{\circ}, 20^{\circ}$ ) or warm water $\left(44^{\circ}\right)$. We included GVS studies using binaural GVS with the anode located on one mastoid process and the cathode on the opposite side. We also included studies using sounds (short-tone bursts or auditory clicks) which have been shown to induce vestibular-evoked myogenic potentials in the sternocleidomastoid muscles.

(2) Inclusion of healthy participants. We did not include studies involving patients with vestibular deafferentation or populations in which drugs have been tested.

(3) Use of clearly identifiable contrasts between a type of vestibular stimulation and a control condition [e.g., CVS > rest (Dieterich et al., 2003); GVS > painful electrical stimulation at $\mathrm{C}_{5 / 6}$ (Bense et al., 2001)].
(4) Availability of 3D coordinates of activation $(x, y, z)$ according to either the atlas of Talairach and Tournoux (1988) or the Montreal Neurological Institute (MNI) space. Authors were personally contacted to obtain the coordinates of activation if they were not provided in the publication already.

(5) Whole-brain volume or most of the supratentorial brain was scanned.

All in all, we included a total of 25 contrasts reported in 16 articles and carried out in a total of 192 healthy participants. The selected publications are listed in Table 1, together with the type of vestibular stimulation, number of participants and number of foci reported for each contrast. To summarize, the

Table 1. List of neuroimaging studies included in the ALE meta-analysis. Columns A1-A5 identify the activation foci included in the five ALE metaanalyses (see Methods). CVS: caloric vestibular stimulation, GVS: galvanic vestibular stimulation, RH: right-handed participants, LH: left-handed participants, MNI: Montreal Neurological Institute coordinates; fMRI: functional magnetic resonance imaging, PET: positron emission tomography, MEG: magnetoencephalography

\begin{tabular}{|c|c|c|c|c|c|c|c|c|c|c|c|}
\hline Publications & Subjects & $\begin{array}{l}\text { Imaging } \\
\text { modality }\end{array}$ & Stimulus & Left ear & Right ear & $\begin{array}{l}\text { Reported } \\
\text { foci }\end{array}$ & A1 & $\mathrm{A} 2$ & A3 & A4 & A5 \\
\hline \multirow[t]{2}{*}{ Bottini et al. (1994) } & $6 \mathrm{RH}$ & PET $\left(\mathrm{H}_{2}{ }^{15} \mathrm{O}\right)$ & CVS & Iced water & - & 7 & $\times$ & & & $\times$ & \\
\hline & & & CVS & - & Iced water & 8 & $\times$ & & & & $x$ \\
\hline Bottini et al. (2001) & $3 \mathrm{RH}$ & PET $\left(\mathrm{H}_{2}{ }^{15} \mathrm{O}\right)$ & CVS & Iced water & - & 38 & $x$ & & & $x$ & \\
\hline \multirow[t]{2}{*}{ Suzuki et al. (2001) } & $12 \mathrm{RH}$ & fMRI $(1.5 \mathrm{~T})$ & CVS & Water $4^{\circ}$ & - & 13 & $x$ & & & $x$ & \\
\hline & & & CVS & - & Water $4^{\circ}$ & 8 & $x$ & & & & $\times$ \\
\hline \multirow[t]{2}{*}{ Emri et al. (2003) } & $6 \mathrm{RH}$ & $\begin{array}{l}\text { PET } \\
\left({ }^{15} \mathrm{O}-\text { butanol }\right)\end{array}$ & CVS & Water $0^{\circ}$ & - & 23 & $\times$ & & & $x$ & \\
\hline & & & CVS & - & Water $0^{\circ}$ & 21 & $x$ & & & & $x$ \\
\hline Indovina et al. (2005) & $17 \mathrm{RH}$ & fMRI (1.5 T) & CVS & Water $10^{\circ}$ & Water $10^{\circ}$ & 17 & $x$ & & & & \\
\hline \multirow{4}{*}{$\begin{array}{l}\text { Dieterich et al. } \\
\text { (2003) }\end{array}$} & $12 \mathrm{RH}$ & PET $\left(\mathrm{H}_{2}{ }^{15} \mathrm{O}\right)$ & CVS & Water $44^{\circ}$ & - & 16 & $\times$ & & & & $\times$ \\
\hline & & & cVs & - & Water $44^{\circ}$ & 22 & $x$ & & & $x$ & \\
\hline & $12 \mathrm{LH}$ & PET $\left(\mathrm{H}_{2}{ }^{15} \mathrm{O}\right)$ & CVS & Water $44^{\circ}$ & - & 34 & $\hat{x}$ & & & & $x$ \\
\hline & & & CVS & - & Water $44^{\circ}$ & 34 & $x$ & & & $x$ & \\
\hline $\begin{array}{l}\text { Deutschländer et al. } \\
\text { (2002) }\end{array}$ & $\begin{array}{l}12 \mathrm{RH}, \\
1 \mathrm{LH}\end{array}$ & PET $\left(\mathrm{H}_{2}{ }^{15} \mathrm{O}\right)$ & CVS & - & Water $44^{\circ}$ & 15 & $\times$ & & & $x$ & \\
\hline $\begin{array}{l}\text { Hegemann et al. } \\
\text { (2003) }\end{array}$ & $9 \mathrm{RH}^{*}$ & $\begin{array}{l}\text { MEG } \\
\text { (31-channel SQUID) }\end{array}$ & CVS & & Water $20^{\circ}$ & $1^{*}$ & $x$ & & & & $\times$ \\
\hline Marcelli et al. (2009) & $9 \mathrm{RH}$ & fMRI $(1.5 \mathrm{~T})$ & CVS & Water $4^{\circ}$ & - & $4^{*}$ & $x$ & & & $\times$ & \\
\hline Lobel et al. (1998) & $6 \mathrm{RH}$ & fMRI $(1.5 \mathrm{~T})$ & GVS & $\begin{array}{l}\text { Synergistic stimu } \\
\text { labyrinths with }\end{array}$ & $\begin{array}{l}\text { llation of left/right } \\
1 \mathrm{~Hz} \text { sinusoids }\end{array}$ & 7 & & $\times$ & & & \\
\hline Bense et al. (2001) & $6 \mathrm{RH}$ & fMRI $(1.5 \mathrm{~T})$ & GVS & Cathode left/ri & ight/alternate ${ }^{a}$ & 18 & & $x$ & & & \\
\hline \multirow{2}{*}{$\begin{array}{l}\text { Eickhoff et al. } \\
\qquad(2006 a, b)^{b}\end{array}$} & $11 \mathrm{RH}$ & fMRI $(1.5 \mathrm{~T})$ & GVS & Anode left & Cathode right & 3 & & $\times$ & & $x$ & \\
\hline & & & GVS & Cathode left & Anode right & 5 & & $\times$ & & & $x$ \\
\hline Stephan et al. (2005) & $21 \mathrm{RH}$ & fMRI $(1.5 \mathrm{~T})$ & GVS & $\begin{array}{r}\text { Sinusoidal } \mathrm{G} \\
\text { both ma }\end{array}$ & $\begin{array}{l}\text { VS between } \\
\text { astoids }{ }^{c}\end{array}$ & 25 & & $\times$ & & & \\
\hline Miyamoto et al. (2007) & $12 \mathrm{RH}^{*}$ & fMRI (1.5 T) & Sounds & Click $102 \mathrm{~dB}$ & - & 15 & & & $x$ & & $\times$ \\
\hline \multirow[t]{2}{*}{$\begin{array}{l}\text { Schlindwein et al. } \\
\text { (2008) }\end{array}$} & $21 \mathrm{RH}$ & fMRI $(1.5 \mathrm{~T})$ & Sounds & $\begin{array}{l}102 \mathrm{~dB} \text { short-tone } \\
\text { burst at } 500 \mathrm{~Hz}\end{array}$ & - & 1 & & & $\times$ & & $x$ \\
\hline & & & Sounds & - & $\begin{array}{l}102 \mathrm{~dB} \text { short-tone } \\
\text { burst at } 500 \mathrm{~Hz}\end{array}$ & 2 & & & $x$ & $x$ & \\
\hline \multirow[t]{2}{*}{ Janzen et al. (2008) } & $16 \mathrm{LH}$ & fMRI $(1.5 \mathrm{~T})$ & Sounds & $102 \mathrm{~dB}$ & - & 6 & & & $x$ & & \\
\hline & & & Sounds & - & $102 \mathrm{~dB}$ & 9 & & & $\times$ & & \\
\hline \multirow[t]{3}{*}{$\begin{array}{l}\text { Total: } 16 \text { studies } \\
\text { ( } 25 \text { experiments })\end{array}$} & $\begin{array}{l}192 \\
\text { subjects }\end{array}$ & 5 PET & 9 CVS & & & 352 & 261 & 58 & 33 & 161 & 109 \\
\hline & & $10 \mathrm{fMRI}$ & 4 GVS & & & & & & & & \\
\hline & & $1 \mathrm{MEG}$ & 3 sounds & & & & & & & & \\
\hline
\end{tabular}

* Personal communication from the authors.

a The cathode was always on the left mastoid for two subjects, always on the right mastoid for two subjects, and once on the left and once on the right mastoid for two subjects.

b The authors reanalyzed the fMRI experiment by Fink et al. (2003) whose original data were not included in the present meta-analysis.

${ }^{c}$ Eleven subjects received sinusoidal GVS at the frequency of $0.1,1.0$, and $5.0 \mathrm{~Hz}$ and 10 subjects at $0.3,0.8$, and $2.0 \mathrm{~Hz}$. 
studies included in the present meta-analysis used fMRI $(n=10)$, PET $(n=5)$ and MEG $(n=1)$ as neuroimaging techniques, and CVS $(n=9)$, GVS $(n=4)$ and sounds $(n=3)$ as vestibular stimulation methods.

\section{ALE algorithm and procedures}

The present meta-analysis used the ALE algorithm developed by Turkeltaub et al. (2002) that was modified later to control for false discovery rate (Laird et al., 2005). This algorithm has been developed further by Eickhoff et al. (2009) to explicitly model the uncertainty associated with a given activation focus and to allow for random-effects analysis. This revised version of the ALE algorithm is implemented in the GingerALE (version 2.0.4) software from BrainMap released in 2010 (Research Imaging Institute of the University of Texas Health Science Center San Antonio; http://brainmap.org/ale/) and was used for the analyses we report in this article.

Before analysis, coordinates reported according to the Talairach and Tournoux space were converted into MNI coordinates using a linear transformation implemented in GingerALE (Lancaster et al., 2007) in order to work in a common stereotactic space (for similar procedures, see Caspers et al., 2010).

Each activation focus imported in GingerALE was modeled by a localization probability with a 3D-Gaussian distribution whose center was at the $x, y, z$ coordinates reported in the MNI space. The uncertainty related to each focus localization was modeled by the full-width at half-maximum of the Gaussian function that was determined separately for each experiment based on the number of participants included (for details, see Eickhoff et al., 2009). This procedure created a 3-dimensional ALE map in which each voxel was assigned a value corresponding to the combination of the localization probabilities of the activation foci. In parallel, it was determined for each voxel the null-distribution of the ALE statistics based on random generation of activation foci. Finally, the spatial convergence of the activation foci was statistically evaluated by comparing the ALE map with the nulldistribution generated for each voxel (Eickhoff et al., 2009). All statistical maps were thresholded using a false discovery rate for $P<0.05$ (corrected for multiple comparisons; see Laird et al., 2005) and using a minimum cluster size of $100 \mathrm{~mm}^{3}$.

Three ALE maps were calculated separately to differentiate the influence of the type of vestibular stimulation (see Table 1):

- (A1) Analysis 1: "CVS". An ALE map was calculated to describe brain regions activated by CVS, irrespective of the ear being stimulated.
- (A2) Analysis 2: "GVS". An ALE map was calculated to describe brain regions activated by GVS, irrespective of the ear being stimulated.

- (A3) Analysis 3: "sounds". An ALE map was calculated to describe brain regions activated by auditory clicks and short-tone bursts, irrespective of the ear being stimulated.

Two additional ALE maps were calculated to describe the laterality of vestibular projections and the hemispheric dominance of vestibular processing. Because the laterality of vestibular projections has been shown to interact with participant's handedness (Dieterich et al., 2003), these ALE maps have been calculated using data from studies that included only righthanded participants (there were not enough studies available to calculate separate ALE maps for left-handed participants). Studies have been divided into two groups: those using vestibular stimulations that simulate a "relative right-ear activation", i.e. an activation close to that usually present during a head rotation or translation directed to the right, and those using vestibular stimulation that simulate a "relative left-ear activation" (Table 1). This means that we took into account the behavioral consequences of each type of vestibular stimulation and pooled methods resulting in similar behavioral consequence. The different methods and paradigms used to create a relative right-ear activation and left-ear activation are summarized in Table 2. The following ALE maps have been calculated:

- (A4) Analysis 4: "relative right-ear activation". An ALE map was calculated to describe brain regions responding to a "relative" right-ear activation (i.e. right-ear "excitation" or left ear "inhibition"). This includes studies irrigating the right external auditory canal with warm water, studies irrigating the left ear with cold water, studies using binaural GVS with the cathode to the right side and the anode to the left side (excluding studies using sinusoidal GVS between both mastoids), and studies using clicks and short-tone bursts presented to the right ear only.

- (A5) Analysis 5: "relative left-ear activation". An ALE map was calculated to describe brain regions responding to a "relative" left-ear activation during experimental conditions opposite to those described for "Analysis 4".

Results of the ALE meta-analysis were visualized on an average anatomical template coregistered in the MNI coordinate system ("Colin_27_T1_seg_MNI.nii" available on http://brainmap. org/ale/) using Mango 2.4 (http://ric.uthscsa.edu/mango/). Activations located in the Sylvian fissure were visualized and

Table 2. List of methods used to simulate an apparent activation of the right ear versus left ear

\begin{tabular}{|c|c|c|c|}
\hline \multicolumn{2}{|c|}{ Relative right-ear excitation } & \multicolumn{2}{|c|}{ Relative left-ear excitation } \\
\hline Right warm CVS & $\begin{array}{l}\text { - Self-motion perception: directed towards the right } \\
\text { mostly rotations around the roll and yaw axes, also } \\
\text { translations along the antero-posterior axis, } \\
\text { sensation of sinking (Kolev, 2001) } \\
\text { - Nystagmus: slow phases directed towards the left }\end{array}$ & $\begin{array}{l}\text { Left warm } \\
\text { CVS }\end{array}$ & $\begin{array}{l}\text { - Self-motion perception: directed towards the left } \\
\text { mostly rotations around the roll and yaw axes, also } \\
\text { translations along the antero-posterior axis, } \\
\text { sensation of sinking (Kolev, 2001) } \\
\text { - Nystagmus: slow phases directed towards the right }\end{array}$ \\
\hline Left cold CVS & $\begin{array}{l}\text { - Self-motion perception: directed towards the right, } \\
\text { see above } \\
\text { - Nystagmus: slow phases directed towards the left }\end{array}$ & $\begin{array}{l}\text { Right cold } \\
\text { CVS }\end{array}$ & $\begin{array}{l}\text { - Self-motion perception: directed towards the left, } \\
\text { see above } \\
\text { - Nystagmus: slow phases directed towards the right }\end{array}$ \\
\hline $\begin{array}{l}\text { Right cathodal } \\
\text { GVS }\end{array}$ & $\begin{array}{l}\text { - Self-motion perception: directed towards the right } \\
\text { (Fitzpatrick and Day, 2004) mostly around the yaw } \\
\text { axis, also around the roll axis (Stephan et al., 2005) } \\
\text { mostly whole-body self-motion, also only head } \\
\text { motion } \\
\text { - Nystagmus: slow phases directed towards the left }\end{array}$ & $\begin{array}{l}\text { Left } \\
\text { cathodal } \\
\text { GVS }\end{array}$ & $\begin{array}{l}\text { - Self-motion perception: directed towards the left } \\
\text { (Fitzpatrick and Day, 2004) mostly around the yaw } \\
\text { axis, also around the roll axis (Stephan et al., 2005) } \\
\text { mostly whole-body self-motion, also only head } \\
\text { motion } \\
\text { - Nystagmus: slow phases directed towards the right }\end{array}$ \\
\hline Right clicks & $\begin{array}{l}\text { - No self-motion, or self-motion (tilt) to the right } \\
\text { (Schlindwein et al., 2008; Janzen et al., 2008) }\end{array}$ & Left clicks & $\begin{array}{l}\text { - No self-motion, or self-motion (tilt) to the left } \\
\text { (Schlindwein et al., 2008; Janzen et al., 2008) }\end{array}$ \\
\hline
\end{tabular}


superimposed to the cerebral cortex on inflated hemispheres from the PALS atlas (Van Essen, 2005), using the BrainShow software (Galati et al., 2008) implemented in Matlab (The MathWorks Inc., Natick, MA, USA).

Activations in the insula were labeled as defined in Bense et al. (2001): the anterior insula was defined as comprising three short insular gyri (I, II, III) located anterior to the central insular sulcus, and the posterior insula as comprising two long insular gyri (IV and V) located posterior to the central insular sulcus. There is no clear definition of the localization of the retroinsular cortex in humans and we considered the retroinsular cortex as the territory posterior to the long insular gyrus $\mathrm{V}$ (Bense et al., 2001; see also Indovina et al., 2005), "where the upper bank of the parietal operculum joins the lower bank of the temporal operculum" (Augustine, 1996). Clusters located in the cerebellum were labeled according to the three-dimensional MRI atlas of Schmahmann et al. (1999).

\section{RESULTS}

\section{Significant clusters for CVS}

The ALE meta-analysis revealed eight significant clusters related to CVS. Cluster locations are illustrated in Figs. 2 and 3 (red colors) ${ }^{1}$ and the coordinates and ALE values of the local maxima are reported for each cluster in Table 3a. The two largest clusters were found in similar locations in the right and the left cerebral hemisphere and covered the insula, parieto-frontal operculum, retroinsular cortex, the most posterior part of the superior temporal gyrus, basal ganglia (putamen and claustrum), and the posterior thalamus (pulvinar). Temporal activations also extended to Heschl's gyrus (transverse temporal gyrus, BA 41/42). Activations in the insula were mainly located in the second and third short insular gyri (II and III, anterior insula) and in the two long insular gyri (IV and V, posterior insula). Six additional clusters were found in the caudal part of the left and right anterior cingulate gyrus (BA 24 and 32), left precuneus (BA 7), left superior frontal gyrus (BA 6), and left precentral/postcentral gyrus.

\section{Significant clusters for GVS}

Twelve significant clusters related to GVS were revealed by the ALE meta-analysis (see Figs. 2 and 3: green colors, and Table 3b). The clusters were located in the right Sylvian fissure and covered the posterior part of the parietal operculum, frontal operculum (BA 44/6) and inferior parietal lobule (BA 40). On the left side, significant clusters were located in the Sylvian fissure at the level of the insula, parietal operculum, retroinsular cortex, frontal operculum, precentral gyrus (BA 44) and left inferior parietal lobule (BA 40). Activations in the insula were located in gyri III (anterior insula) and IV (posterior insula). Another cluster was located more ventrally in the posterior part of the middle temporal gyrus (BA 37/19). Thalamic activation was found in the ventral lateral nucleus, extending posteriorly into the ventral posterior lateral nucleus. Another cluster was located in the anterior lobe of the left cerebellum at the immediate anterior part of the superior posterior fissure (cerebellar lobule $\mathrm{VI}$ ).

\footnotetext{
${ }^{1}$ For interpretation of color in Figs. 2 and 3, the reader is referred to the web version of this article.
}

\section{Significant clusters for sounds (saccular) stimulation}

The ALE meta-analysis conducted on the effects of saccular stimulations evoked by sounds included fewer activation foci $(n=3)$ than the two previous analyses. Due to the small sample of foci included in the analysis, this result has to been seen carefully (see Discussion). We report in Figs. 2 and 3 (blue colors) and in Table $3 \mathrm{c}$ the location of the significant clusters. Activations were found in the most posterior part of the right and left Sylvian fissures, where the parietal cortex joins the superior temporal gyrus, presumably at the level of the parietal operculum and retroinsular cortex. The activations extended into the left superior temporal gyrus and Heschl's gyrus (BA 41), as well as into the right superior temporal gyrus (BA 22).

\section{Overlap between the different types of vestibular stimulation}

Significant clusters reported for CVS, GVS, and sounds were located in the insular cortex as well as in the parietal and temporal banks of the Sylvian fissure, as shown in inflated renderings of the right and left cerebral hemispheres (Fig. 3). Fig. 4 illustrates selected slices of the brain regions commonly reported in the ALE metaanalyses described in the previous sections.

The area colored in white represents the conjunction (spatial overlap) between regions activated by CVS, GVS, and sounds (Fig. 4A). Only one small region showed an overlap of all three stimulation techniques and was located at the junction between the inferior parietal lobule and the superior temporal gyrus. The activation was located in the retroinsular cortex, the region of cortex located immediately posterior to OP2 and OP1 (as defined by the probabilistic maps illustrated in Fig. 4B).

Areas colored in yellow in Fig. $4 \mathrm{~A}^{2}$ represent the conjunction between regions activated by CVS and GVS. These regions were found in the left posterior insula (long insular gyrus IV), anterior insula (short insular gyrus III), in the bilateral parietal operculum (OP2) and retroinsular cortex. Regions responding to both CVS and sounds (represented in magenta) were located in the bilateral retroinsular cortex, posterior to OP2 (see Fig. 4B). Finally, a region responding to GVS and sounds (represented in cyan) was found in the left retroinsular cortex.

\section{Contralateral and ipsilateral vestibular projections}

Fig. 5A illustrates the laterality of vestibular projections in right-handed participants during relative right-ear activation (simulating rightward motion) and relative left-ear activations (simulating leftward motion) (see Table 2 for a summary of the stimulation conditions). The ALE meta-analysis revealed significant clusters located in both the ipsilateral and contralateral cerebral hemispheres with respect to the activated ear, thus revealing bilateral vestibular projections (see Table 4). This was especially the case for the large clusters located in the Sylvian fissure. An additional clear pattern of predominant ipsilateral activation was observed. Fig. $5 \mathrm{~B}$ and $\mathrm{C}$ illustrate the volume

\footnotetext{
${ }^{2}$ For interpretation of color in Fig. 4, the reader is referred to the web version of this article.
} 


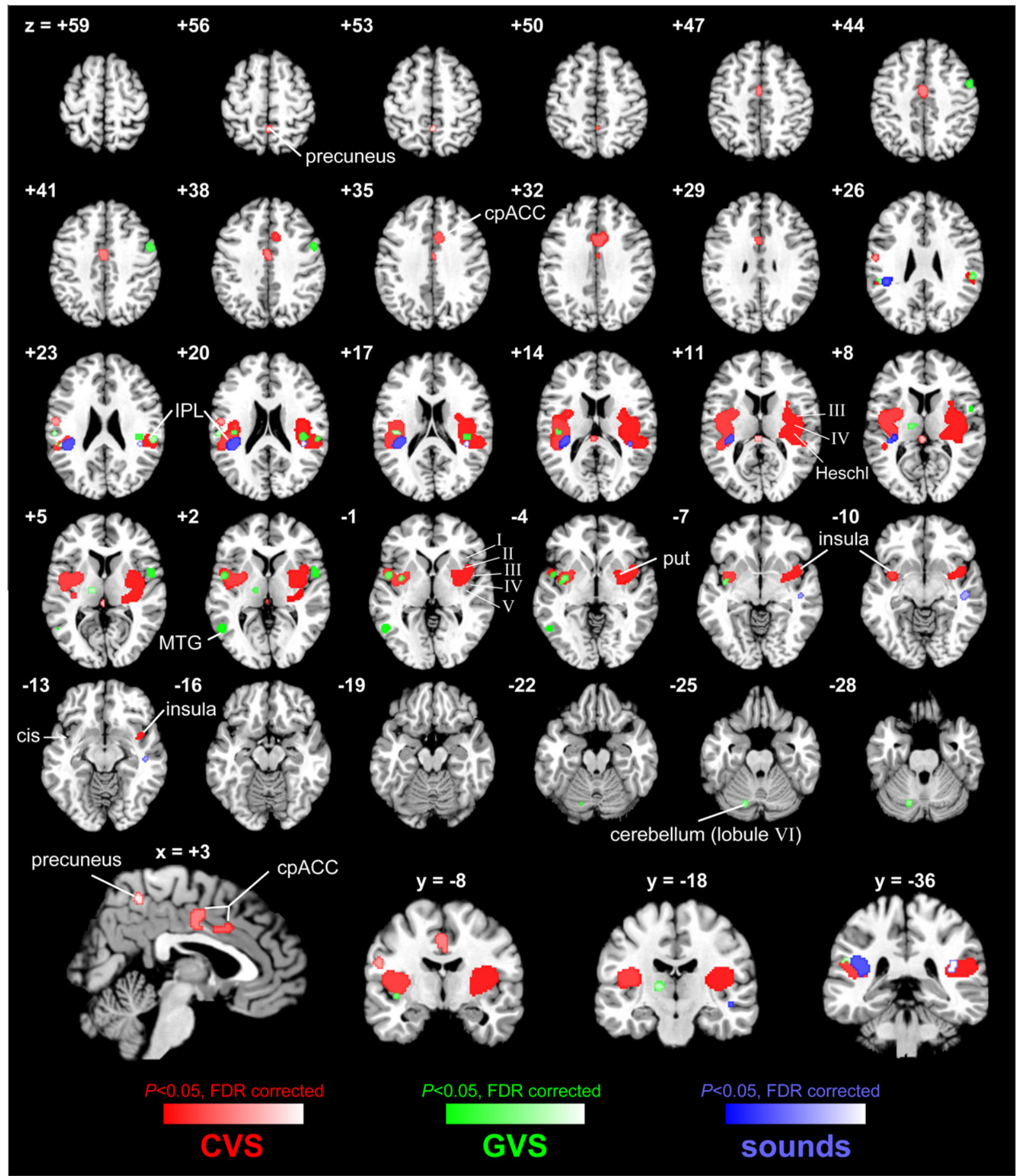

Fig. 2. Localization of significant clusters identified by the meta-analysis for CVS (Analysis 1), GVS (Analysis 2), and sounds (Analysis 3 ) irrespective of the side of the stimulation. All results are displayed on selected brain slices from a single subject template in the MNI space. All values are corrected for false discovery rate $(P<0.05)$

of the clusters located in the Sylvian and peri-Sylvian region. The data show that clusters in the Sylvian region ipsilateral to the activated ear are larger than the clusters located in the contralateral Sylvian region. In other worlds, relative right-ear activation resulted in larger clusters in the right cerebral hemisphere than in the left hemisphere. Conversely, relative left-ear activation resulted in an overall larger pattern of activations in the left hemisphere.

\section{DISCUSSION}

The present ALE meta-analysis was conducted to aid localization of human vestibular cortex, which has so far been investigated using several stimulation methods (CVS, GVS, sounds) involving different subcategories of vestibular receptors. The present data describe brain regions activated by each type of vestibular stimulation 


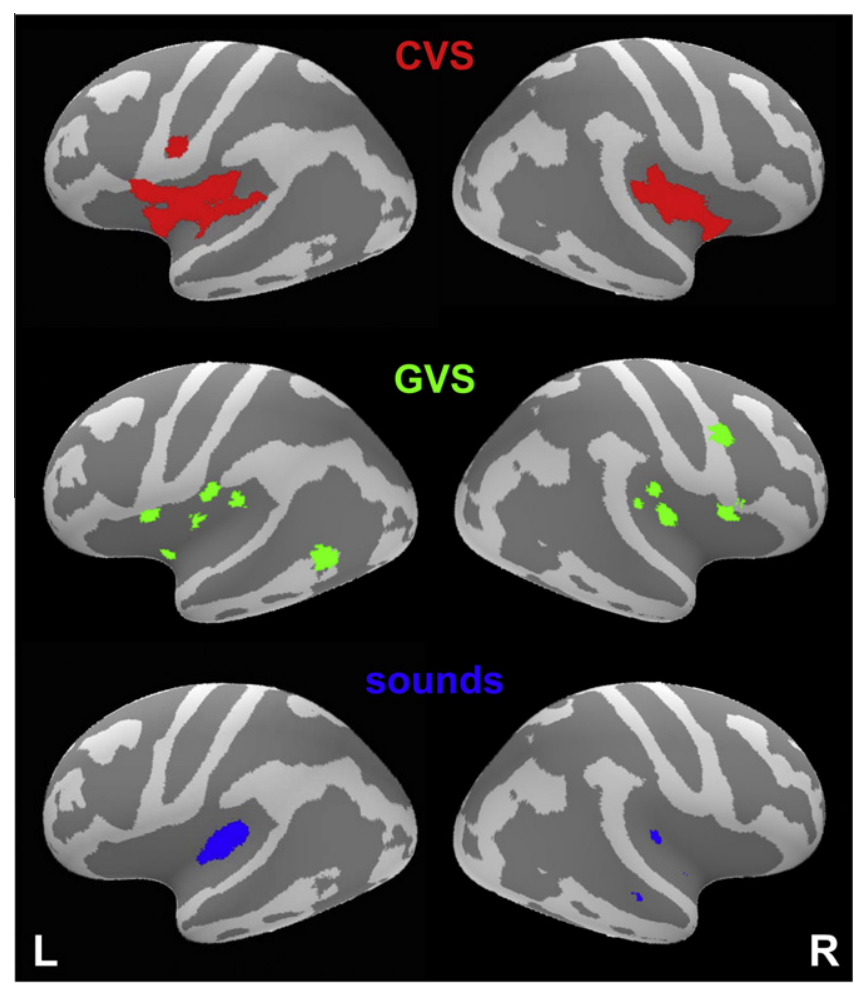

Fig. 3. Localization of significant clusters identified by the meta-analysis for CVS (Analysis 1), GVS (Analysis 2), and sounds (Analysis 3 ) irrespective of the side of the stimulation. Results are displayed on inflated hemispheres to reveal activations in the Sylvian fissure. All values are corrected for false discovery rate $(P<0.05)$.

and allow for a description of three regions (insula, parietal operculum, retroinsular cortex) commonly activated by these types of vestibular stimulation. We also describe one region (retroinsular cortex) that was activated by all stimulation methods.

\section{The human vestibular cortex}

The present meta-analysis demonstrates vestibular processing in seven main regions: the temporoparieto-insular and retroinsular cortex, parietal cortex, frontal cortex, cingulate cortex, and three subcortical structures (thalamus, basal ganglia, and cerebellum).

Temporo-parieto-insular and retroinsular activations. The largest clusters of activation were found in the Sylvian fissure, at the level of the insula and retroinsular region, as well as at the temporal and parietal banks of the Sylvian fissure.

Significant clusters were associated with CVS in the posterior insula (long insular gyri III and IV) and caudal part of the anterior insula (short insular gyri II and III), while GVS was associated with clusters in the posterior insula (long insular gyri III and IV), and sounds mainly in the retroinsular cortex. The posterior insula and surrounding areas have been proposed by some authors as being the core vestibular cortex in both animals (Guldin and Grüsser, 1998) and humans (Brandt and Dieterich, 1999). Electrophysiological studies in primates demonstrated vestibular neurons "within the most posterior and upper part of the insular cortex" (Grüsser et al.,
1990). These authors found vestibular neurons in the insular granular field (lg), but not in the dysgranular insular cortex (Id) and anterior insula. We note that neuroimaging studies controlling for nociceptive tactile stimulation (in the case of GVS) revealed activations in the posterior insula only (Bucher et al., 1998). It is therefore possible that part of the activations previously reported in the median and anterior insula may be related to concurrent thermal, nociceptive and vegetative sensations (Craig, 2009; Baumgartner et al., 2010; Kurth et al., $2010 \mathrm{~b})$. Thus, the common activation within the posterior part of the insula during CVS, GVS, and sounds strongly suggest a vestibular representation in the posterior insula. Direct evidence of vestibular representation in the insula arises from electrical stimulation of this structure in conscious epileptic patients reporting self-motion perception (Isnard et al., 2004; Nguyen et al., 2009).

In addition to the insula, the present meta-analysis shows a robust activation of the retroinsular cortex. Recent mapping of the human insular region based on postmortem brains indicates that the retroinsular cortex is located posteriorly to the insular granular field $(\lg 1)$ and borders the caudal part of the parietal operculum (OP2) (Eickhoff et al., 2006a; Kurth et al., 2010a). The cytoarchitectonic organization of the retroinsular region is intermediate between that of OP2 and the inferior parietal cortex (Eickhoff et al., 2006a) and this region is reciprocally connected with the insular granular field (Ig) (Augustine, 1996). The insula and retroinsular cortex are suggested to be involved in gravity-related processing on the basis of vestibular and visual motion signals 
Table 3. Clusters identified by the meta-analysis for CVS (Analysis 1), GVS (Analysis 2) and sounds (Analysis 3) irrespective of the side of the stimulation. Significant clusters are listed with their volume, together with the activation likelihood estimation (ALE) value and stereotaxic coordinates $(x, y, z)$ in the MNI space of the local maxima

\begin{tabular}{|c|c|c|c|c|c|c|}
\hline \multirow[t]{2}{*}{ Cluster number } & \multirow[t]{2}{*}{ Cluster volume $\left(\mathrm{mm}^{3}\right)$} & \multirow[t]{2}{*}{$\operatorname{ALE}\left(\times 10^{-3}\right)$} & \multicolumn{3}{|c|}{ MNI coordinates } & \multirow[t]{2}{*}{ Cluster location } \\
\hline & & & $x$ & $y$ & $z$ & \\
\hline \multicolumn{7}{|c|}{ (a) Caloric vestibular stimulation (CVS) } \\
\hline \multirow[t]{6}{*}{1} & 18,960 & 28.17 & 40 & -16 & 16 & Right parietal operculum, insula (gyrus IV) \\
\hline & & 27.17 & 34 & 0 & 2 & Right putamen, claustrum, external capsule \\
\hline & & 21.72 & 52 & -32 & 18 & Right superior temporal gyrus (BA 41) \\
\hline & & 20.58 & 42 & 8 & -6 & Right insula (gyri II, III) \\
\hline & & 17.37 & 24 & -24 & 8 & Right posterior thalamus (pulvinar) \\
\hline & & 11.47 & 30 & 12 & 10 & Right frontal operculum, insula (gyrus II) \\
\hline \multirow[t]{7}{*}{2} & 14,568 & 27.32 & -34 & 0 & 8 & Left claustrum, insula (gyrus III), extreme capsule \\
\hline & & 25.54 & -42 & -2 & 6 & Left insula (gyrus III) \\
\hline & & 25.52 & -38 & -18 & 14 & Left insula (gyrus IV) \\
\hline & & 23.30 & -44 & -32 & 18 & Left parietal operculum/retroinsular cortex (OP1/Ri), superior temporal gyrus \\
\hline & & 19.96 & -36 & 2 & -6 & Left insula (gyrus III), claustrum, extreme capsule \\
\hline & & 17.25 & -52 & 6 & 0 & Left frontal operculum (BA 6/44) \\
\hline & & 15.00 & -54 & -36 & 22 & Left parietal operculum/retroinsular cortex (OP1/Ri) \\
\hline \multirow[t]{2}{*}{3} & 1272 & 17.37 & 8 & 16 & 36 & Right anterior cingulate gyrus, caudal part (BA 32/24) \\
\hline & & 12.75 & -2 & 10 & 32 & Left anterior cingulate gyrus, caudal part (BA 24/32) \\
\hline 4 & 1176 & 17.62 & -2 & -4 & 44 & Left anterior cingulate gyrus, caudal part (BA 24) \\
\hline 5 & 448 & 15.70 & -56 & -8 & 24 & Left central sulcus, postcentral/precentral gyrus \\
\hline 6 & 432 & 12.72 & -4 & -28 & 12 & Left posterior thalamus (pulvinar) \\
\hline 7 & 216 & 13.48 & 0 & -48 & 56 & Left precuneus (BA 7) \\
\hline 8 & 112 & 12.85 & -12 & 2 & 74 & Left superior frontal gyrus (BA 6) \\
\hline \multicolumn{7}{|c|}{ (b) Galvanic vestibular stimulation (GVS) } \\
\hline 1 & 496 & 12.86 & -54 & -58 & 2 & Left middle temporal gyrus (BA 37/19) \\
\hline 2 & 480 & 10.70 & 54 & 6 & 4 & Right frontal operculum, precentral gyrus (BA 44) \\
\hline 3 & 456 & 12.38 & 40 & -26 & 22 & Right parietal operculum (OP2) \\
\hline 4 & 456 & 11.04 & 52 & 2 & 44 & Right frontal operculum, precentral gyrus, inferior frontal gyrus (BA 6/44) \\
\hline 5 & 328 & 9.89 & -52 & 2 & 2 & Left frontal operculum, precentral gyrus (BA 44) \\
\hline 6 & 304 & 9.17 & -36 & 0 & -2 & Left insula (gyri IV and III), claustrum, extreme capsule \\
\hline 7 & 272 & 9.85 & v18 & -70 & -28 & Left cerebellum (anterior lobe, lobuleVI) \\
\hline 8 & 272 & 9.66 & 56 & -28 & 24 & Right inferior parietal lobule (BA 40) \\
\hline 9 & 264 & 9.88 & -16 & -14 & 6 & Left thalamus (ventral lateral nucleus, ventral posterior lateral nucleus) \\
\hline \multirow[t]{2}{*}{10} & 168 & 7.56 & -44 & -20 & 16 & Left parietal operculum (OP2) \\
\hline & & 7.55 & -40 & -22 & 20 & Left parietal operculum (OP2) \\
\hline 11 & 144 & 8.72 & -58 & -22 & 22 & Left inferior parietal lobule (BA 40) \\
\hline \multirow[t]{2}{*}{12} & 128 & 7.68 & -50 & -36 & 26 & Left parietal operculum/retroinsular cortex (OP1/Ri) \\
\hline & & 6.77 & -56 & -34 & 24 & Left parietal operculum/retroinsular cortex (OP1/Ri) \\
\hline \multicolumn{7}{|c|}{ (c) Sounds (saccular stimulation) } \\
\hline \multirow[t]{2}{*}{1} & 2192 & 18.61 & -44 & -36 & 24 & Left parietal operculum/retroinsular cortex (OP1/Ri) \\
\hline & & 8.50 & -42 & -32 & 8 & Left superior temporal gyrus, Heschl's gyrus (BA 41) \\
\hline 2 & 368 & 11.55 & 46 & -20 & -8 & Right superior temporal gyrus (BA 22) \\
\hline 3 & 256 & 9.49 & 40 & -34 & 22 & Right parietal operculum/retroinsular cortex (OP1/Ri) \\
\hline
\end{tabular}




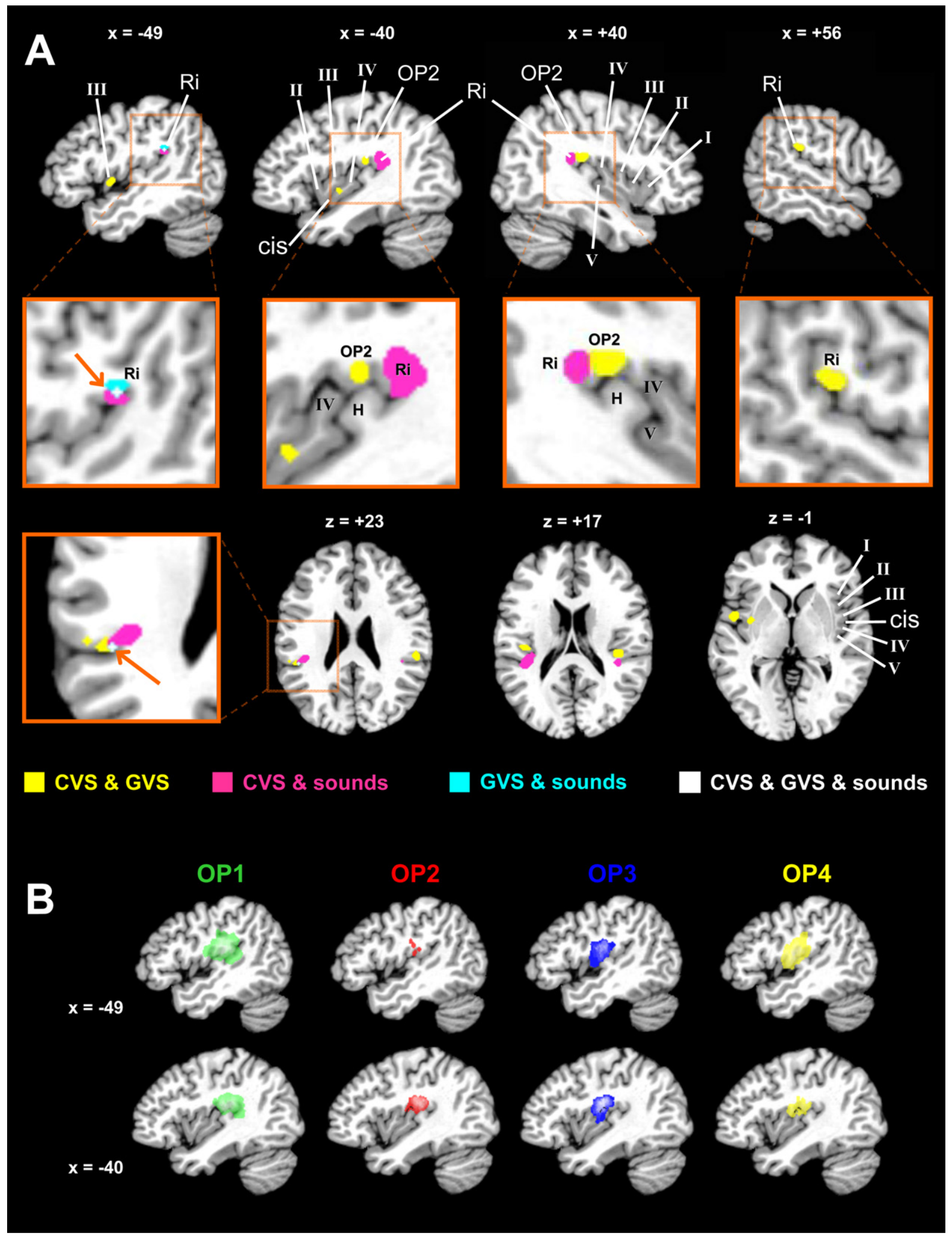

Fig. 4. Spatial overlap between activations related to CVS, GVS, and sounds. (A) Voxels in yellow, magenta, and cyan represent the overlap between two techniques of vestibular stimulation. The area colored in white (and pointed by an orange arrow) represents the area of overlap between all three techniques of vestibular stimulation. The localization in the insula is given according to Bense et al. (2001): I, II, III: short insular gyri in the anterior insula; IV and VI: long insular gyri in the posterior insula; cis: central insular sulcus; H: Heschl's gyrus; Ri: retroinsular cortex; OP: parietal operculum. (B) Probabilistic maps of the four cytoarchitectonic regions of the parietal operculum (OP1-4) are projected on sagittal slices of a single subject template matching the level of the slices pictured in part (A). Plotted after the data from Eickhoff et al. (2006a). 


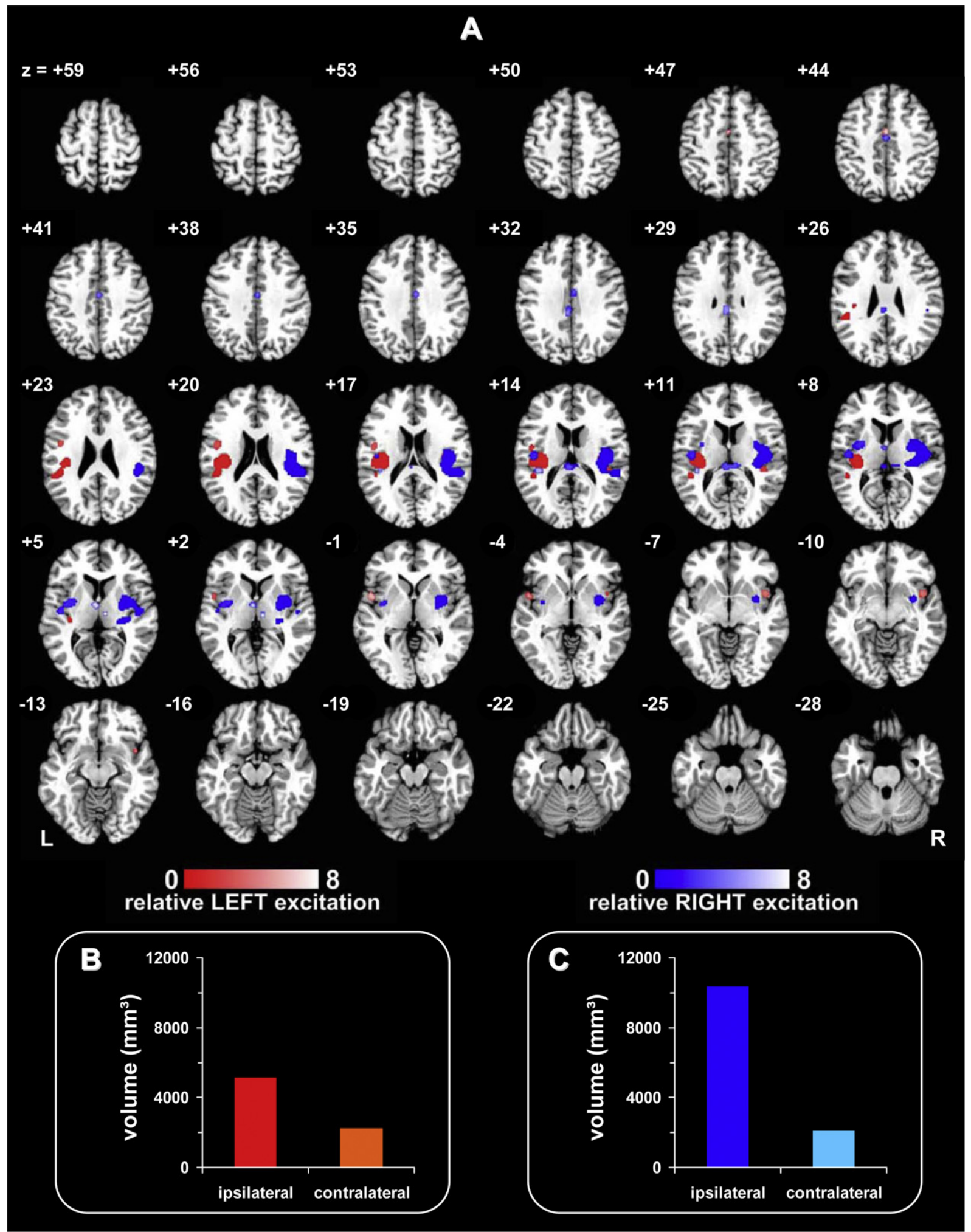

Fig. 5. Laterality of vestibular projections. The localization of significant clusters identified by the meta-analysis for relative left-ear excitation (Analysis 4) and relative right-ear excitation (Analysis 5) is displayed on horizontal brain slices from a single subject template in the MNI space. All values are corrected for false discovery rate $(P<0.05)$.

(Indovina et al., 2005). The present observation of insular and retroinsular activations during vestibular stimulation is consistent with electrophysiological recordings in monkeys showing that vestibular-responsive neurons are located "in the upper bank of the lateral sulcus around the posterior end of the insula" (Grüsser et al., 1990). 
Table 4. Clusters identified by the meta-analysis for relative left-ear excitation (Analysis 4) and relative right-ear excitation (Analysis 5). Significant clusters are listed with their volume, together with the activation likelihood estimation (ALE) value and stereotaxic coordinates $(x, y, z)$ in the MNI space of the local maxima

\begin{tabular}{|c|c|c|c|c|c|c|}
\hline \multirow{2}{*}{$\begin{array}{l}\text { Cluster } \\
\text { number }\end{array}$} & \multirow{2}{*}{$\begin{array}{l}\text { Cluster volume } \\
\left(\mathrm{mm}^{3}\right)\end{array}$} & \multirow{2}{*}{$\begin{array}{l}\text { ALE } \\
\left(\times 10^{-3}\right)\end{array}$} & \multicolumn{3}{|c|}{ MNI coordinates } & \multirow[t]{2}{*}{ Cluster location } \\
\hline & & & $x$ & $y$ & $z$ & \\
\hline \multicolumn{7}{|c|}{ (a) Relative right-ear "excitation" } \\
\hline \multirow[t]{6}{*}{1} & 10,392 & 18.80 & 42 & -16 & 14 & Right parietal operculum/posterior insula (gyrus IV) \\
\hline & & 16.31 & 34 & 0 & 2 & Right claustrum/putamen/insula (gyrus III) \\
\hline & & 13.31 & 38 & -26 & 18 & Right parietal operculum (OP2) \\
\hline & & 12.79 & 54 & -34 & 18 & Right superior temporal gyrus (BA 22/40) \\
\hline & & 11.96 & 46 & -34 & 20 & Right parietal operculum \\
\hline & & 11.12 & 26 & -24 & 6 & Right pulvinar/Heschl's gyrus/posterior insula (gyrus IV) \\
\hline \multirow[t]{2}{*}{2} & 1896 & 12.80 & -46 & -14 & 12 & Left parietal operculum/posterior insula (gyrus IV) \\
\hline & & 12.17 & -34 & -2 & 8 & Left anterior insula (gyrus III)/claustrum/putamen \\
\hline \multirow[t]{2}{*}{3} & 552 & 11.29 & -4 & -28 & 14 & Left posterior thalamus (pulvinar) \\
\hline & & 9.48 & 6 & -26 & 12 & Right posterior thalamus (pulvinar) \\
\hline \multirow[t]{2}{*}{4} & 448 & 10.49 & -2 & -10 & 44 & Left/right cingulate gyrus (BA 24) \\
\hline & & 10.03 & 2 & -8 & 34 & Right/left cingulate gyrus (BA 24) \\
\hline 5 & 336 & 9.99 & -4 & -28 & 30 & Left posterior cingulate gyrus (BA 23) \\
\hline 6 & 240 & 10.67 & -40 & -32 & 14 & $\begin{array}{l}\text { Left parietal operculum (OP2), retroinsular cortex (Ri)/Heschl's } \\
\text { gyrus }\end{array}$ \\
\hline 7 & 224 & 10.70 & -4 & -4 & 4 & Left anterior thalamus (ventral anterior nucleus, anterior nucleus) \\
\hline 8 & 112 & 9.75 & 8 & -16 & 4 & Right thalamus (medial dorsal nucleus) \\
\hline \multicolumn{7}{|c|}{ (b) Relative left ear "excitation" } \\
\hline \multirow[t]{3}{*}{1} & 4800 & 24.95 & -38 & -20 & 14 & Left posterior insula (gyrus IV)/left Heschl's gyrus \\
\hline & & 11.41 & -48 & -36 & 24 & Left retroinsular cortex $(\mathrm{Ri})$ \\
\hline & & 9.83 & -46 & -38 & 12 & Left superior temporal gyrus (BA 22) \\
\hline \multirow[t]{2}{*}{2} & 1576 & 10.85 & 40 & -30 & 14 & Right retroinsular cortex (Ri)/parietal operculum (OP2) \\
\hline & & 10.83 & 38 & -16 & 16 & Right posterior insula (gyrus IV) \\
\hline 3 & 424 & 11.13 & -48 & 0 & 22 & Left inferior frontal gyrus/precentral gyrus \\
\hline 4 & 376 & 13.40 & 42 & 10 & -8 & Right anterior insula (gyrus II, III) \\
\hline 5 & 304 & 10.85 & 34 & 0 & 2 & Right putamen/claustrum/anterior insula (gyrus III) \\
\hline 6 & 264 & 11.40 & -52 & 6 & 0 & Left parietal operculum/anterior insula (gyrus III) \\
\hline 7 & 144 & 10.01 & -2 & -2 & 46 & Left cingulate gyrus (BA 24) \\
\hline 8 & 120 & 9.23 & -36 & -2 & 8 & Left anterior insula (gyrus III)/claustrum \\
\hline
\end{tabular}

More recent monkey research, combining electrophysiological and MRI investigation of the PIVC, confirmed that "most PIVC neurons were recorded within area Ri (retroinsular cortex) and in the transition zones between S2 (secondary somatosensory cortex), Ri and Ig (insular granular field)" (Chen et al., 2010).

More superficial aspects of the Sylvian fissure were also activated by vestibular stimulation. Clusters of activation were found to overlap with the parietal and temporal banks of the Sylvian fissure, including Heschl's gyrus, superior temporal gyrus (BA 41 and 22), middle temporal gyrus (BA 37/19) and the inferior parietal lobule (BA 40). The involvement of the superficial aspects of the Sylvian fissure in vestibular processing has been reported in conscious epileptic patients in whom electrical stimulation of the superior and middle temporal gyri and inferior parietal lobule evokes self-motion perception (Penfield, 1957; Blanke et al., 2002; Kahane et al., 2003). Epileptic foci and lesions of the temporo-parietal cortex may also induce seizures with vestibular aurae (Penfield and Kristiansen, 1951; Smith, 1960; Heydrich et al., 2011). In a recent attempt to localize the vestibular cortex in a large sample of epileptic patients, Kahane et al. (2003) investigated vestibular responses after stimulations of a large temporo-parietal region. These authors proposed a vestibular representation in a region they designated as the temporo-peri-Sylvian vestibular cortex: an area "distributed around the posterior part of the insula but clearly located more superficially, without involving the insula strictly speaking". Thus, according to these authors, the vestibular cortex would be localized more superficially than proposed in other studies (Brandt and Dieterich, 1999) and would not necessarily involve the insula (Kahane et al., 2003). The results from the present meta-analysis confirm vestibular processing in the superior temporal gyrus and in the inferior parietal lobule (i.e. in the superficial structures of the Sylvian fissure). However, we observed the most consistent vestibular representation in the depth of the Sylvian fissure involving the insula, the retroinsular region and the parieto-frontal operculum. This is further discussed in the section "Overlap between CVS, GVS and sound-induced activations".

Postero-medial parietal activations. Another significant parietal cluster was found in the postero-medial parietal cortex for CVS, but not for GVS and sounds. The cluster was located in the mesial extent of BA 7, which is the core region of the precuneus. The precuneus has been involved in various cognitive functions such as spatial and mental imagery, processing related to the self, 
and first-person perspective taking (review in Cavanna and Trimble, 2006). Previous neuroimaging studies showed that the precuneus is also involved in the perception of self-motion (Kovacs et al., 2008), in whole-body motor imagery (Jahn et al., 2004) and mental navigation (Ghaem et al., 1997). The vestibular processing in the precuneus suggested by the present meta-analysis is corroborated by clinical studies showing that electrical stimulation of the precuneus may induce self-motion perception (Kahane et al., 2003; Wiest et al., 2004). We note that, to the best of our knowledge, no homologous region has been described in animals as receiving vestibular inputs. Yet, despite the relatively close structure of the medial parietal cortex in humans and other Primates, the exact equivalence between the human and monkey precuneus remains to be precisely determined (Cavanna and Trimble, 2006). Tracer studies in animals indicate that the main subcortical connections of the precuneus originate from the thalamus (ventrolateral nucleus, lateral pulvinar and intralaminar nuclei), the claustrum, caudate nucleus and putamen (Cavanna and Trimble, 2006). Several of these regions were found activated during vestibular stimulation in the present meta-analysis. To date, only the lateral aspect of the parietal area 7 has been shown to receive vestibular signals in animals (Faugier-Grimaud and Ventre, 1989).

Frontal activations. Only few significant clusters were located in the lateral frontal cortex for CVS and GVS, but not for sounds (for medial frontal activations, see the section "Cingulate activations"). No overlap between CVS, GVS and sounds was found in the frontal cortex. CVS and GVS activate the bilateral frontal operculum, often corresponding to the large Sylvian clusters extending to the neighboring frontal lobes. The activations were located in the precentral gyrus and in the inferior frontal gyrus (BA 44 and BA 6). Activation of the most ventral part of the frontal lobes, including the pars opercularis of the inferior frontal cortex, has not been reported in animals. Some authors have proposed that these activations could represent the human equivalent of the monkey's vestibular region located in the anterior and ventral part of premotor area 6 (Lobel et al., 1998). Another significant cluster was found for CVS in the left superior frontal gyrus (BA 6), in the vicinity of the premotor cortex but, more dorsally than the frontal eye fields (Blanke et al., 2000b). Several electrophysiological studies in animals revealed vestibular projections to frontal areas involved in the control of motor and oculomotor functions, such as area 6 , area 4, and the frontal eye fields (Ebata et al., 2004; Fukushima et al., 2004). We note that not all neuroimaging studies were performed in darkness or with eyes closed. Thus, activities in the frontal cortex could be involved in the control of eye movements induced by the vestibular stimulation itself. For example, the frontal eye fields have been involved in the modulation of the caloric vestibular nystagmus by fixation (Naito et al., 2003). This is consistent with the idea that vestibular processing in the frontal cortex controls some aspects of the vestibuloocular reflex, generation of saccades, and smooth pursuit eye movements (Fukushima et al., 2004).
Cingulate activations. Two significant clusters were found at the level of the anterior cingulate cortex (ACC) during CVS, but not during GVS and sounds. The clusters were located in the caudal part of the ACC rather than in the rostral part, two regions that can be dissociated anatomically and functionally (Devinsky et al., 1995; Paus et al., 1998). The caudal part of the ACC, encompassing BA 24 and BA 32, has been involved in attention and motor control (Paus et al., 1993; Devinsky et al., 1995; Paus et al., 1998; Koski and Paus, 2000). Cytoarchitectonic mapping of the caudal part of the ACC showed that this region contains pyramidal neurons involved in the motor control of the arm and hand. Such regions, known as cingulate motor areas, send projections to the spinal cord (Dum and Strick, 1991). Thus, the clusters reported here may represent neural substrates of the vestibular control on motor and spatial functions such as directed attention (Corbetta et al., 1993). A PET study conducted during deep brain stimulation in patients suffering from essential tremor demonstrated that electrical stimulation of part of the vestibular thalamus (the nucleus ventralis intermedius) increased the regional cerebral blood flow in the ipsilateral and contralateral cingulate gyrus (Ceballos-Baumann et al., 2001). This activation of the cingulate gyrus is consistent with anatomical studies in monkeys revealing a vestibular region in the mesial surface of the frontal cortex, a region that Grüsser and colleagues named the "vestibular cingulate region" (Guldin and Grüsser, 1998). Although the vestibular cingulate region is connected with other vestibular regions such as the PIVC, area 3a, and VPS (Guldin and Grüsser, 1998), there is no electrophysiological evidence that neurons in this cortex are activated by vestibular stimulation.

Thalamic activations. The present ALE meta-analysis revealed only a few clusters in the thalamus. This may partly be due to the fact that we used a spatial threshold, restricting the results to clusters whose volume was larger than $100 \mathrm{~mm}^{3}$. Indeed, thalamic activations during vestibular stimulation are likely to be of limited spatial extent because vestibular-responsive neurons are located in small patches distributed in several thalamic regions rather than localized in some specific thalamic nuclei (Meng et al., 2007). Here, we found that CVS involved the pulvinar and that GVS activated the ventral lateral nucleus, extending into the ventral posterior lateral nucleus. No region of overlap was found in the thalamus for CVS, GVS, and sounds.

Activation of the medial pulvinar has been reported during CVS as well as during proprioceptive stimulation of the neck muscles (Bottini et al., 2001). In addition, the pulvinar has been found activated during optokinetic stimulation (Bucher et al., 1997), revealing that the pulvinar is a nucleus where visual, proprioceptive and vestibular signals converge. The pulvinar is considered as a second-order thalamic relay involved in complex thalamo-cortico-thalamic loops (Sherman and Guillery, 2002) and projecting to the extrastriate, temporal and posterior temporal cortex (Jones, 1985). The results of the present meta-analysis are corroborated by the mapping of the vestibular thalamus in various animal species 
(review in Lopez and Blanke, 2011). Electrophysiological recordings in the pulvinar of squirrel and macaque monkeys also revealed neurons responding to vestibular stimulation (Meng et al., 2007; Marlinski and McCrea, 2008). In addition, tracer studies in the squirrel monkey indicated that the lateral pulvinar is connected to the PIVC and area $\mathrm{T} 3$, and that the anterior and medial pulvinar are connected to area 3aV (Akbarian et al., 1992).

The present analysis also revealed a significant cluster in the ventral lateral (VL) nucleus, extending caudally into the ventral posterior lateral nucleus (VPL). Anatomical studies revealed that VL and VPL receive vestibular projections from the vestibular nuclei (Kotchabhakdi et al., 1980). The VL is known to receive projections from the cerebellum (Percheron et al., 1996) and from several cerebellar nuclei such as the fastigial nucleus, dentate nucleus, and anterior interposed nuclei (Meng et al., 2007). The VL provides signals to the motor and premotor cortex (BA 4 and 6) and is certainly involved in the vestibular control of the structures regulating human motion. The VPL is a major relay of tactile and proprioceptive signals to the somatosensory cortex (Jones, 1985). It has also been described as a vestibular relay to several parietal and peri-Sylvian vestibular areas in the cat and monkey (Blum et al., 1979), where vestibular-tactile and vestibular-proprioceptive signals converge.

Basal ganglia and cerebellum. The clusters found in the Sylvian fissure were found to extend into the claustrum and the putamen, overlapping with the extreme and external capsules. The claustrum lies under the surface of the insula from which it is separated by the extreme capsule. It is difficult to conclude from the present meta-analysis whether this represents a specific activation of the claustrum or a spread of the insular activation to the medial part of the brain. Activation of the insula/claustrum region has been reported in previous studies (e.g. during cross-modal transfer of information between touch and vision: Hadjikhani and Roland, 1998). Diffusion tensor imaging and anatomical methods indicate that the claustrum is strongly interconnected with most of the other cortical areas (Fernandez-Miranda et al., 2008) including the insula (Augustine, 1996). The functions of the claustrum are rather unclear but some authors have proposed its involvement in multisensory integration (Hadjikhani and Roland, 1998) and in the generation of conscious percepts (Crick and Koch, 2005).

Other basal ganglia activation found during CVS concerned the putamen. We note that there is only a poor description of vestibular processing in the human putamen. It has been found activated during self-motion perception induced by CVS (Bottini et al., 1994; Dieterich et al., 2003), GVS (Bense et al., 2001), and during visually induced self-motion illusions (Kovacs et al., 2008). The generation of an optokinetic nystagmus and other eye movements has also been related to putamen activation (Dieterich et al., 1998). Therefore, some authors have proposed that the involvement of the putamen during vestibular stimulation could be related to the oculomotor functions of the putamen, which would receive efferent projections from the frontal oculomotor cortex and the anterior insula (Bense et al., 2001). Electrophysiological recordings in squirrel monkeys also corroborated vestibular processing in the putamen (Liedgren and Schwarz, 1976). Moreover, anatomical studies revealed that the putamen, together with the claustrum and the tail of the caudate, is connected with the insula (Augustine, 1996).

We also observed a significant cluster in the anterior lobe (lobule $\mathrm{VI}$ ) of the cerebellum during GVS. A recent ALE meta-analysis investigating cerebellar functions demonstrated that the anterior lobe of the cerebellum, and to a lesser extent lobule $\mathrm{VI}$, contribute to sensorimotor, spatial, and emotional processing (Stoodley and Schmahmann, 2009). The anterior lobe of the cerebellum has been shown to receive afferents from the spinal cord and to be reciprocally connected to the motor cortex. Vestibular projections to the cerebellum are numerous (Büttner-Ennever, 1999) and they control eye movements, body posture (Baier et al., 2008), and adapt the velocity of the caloric vestibular nystagmus (Naito et al., 2003).

\section{Overlap between CVS, GVS and sound-induced activations}

The present meta-analysis revealed that regions showing overlap between two or three vestibular stimulation methods were selectively located in the insula, the parietal operculum, and the retroinsular cortex (Fig. 4).

The middle (short gyrus III) and posterior (long gyrus IV) insular cortex showed convergence between CVS and GVS, suggesting that this area receives afferents from all types of vestibular receptors. As stated above, electrophysiological recordings in monkeys revealed vestibular responses in the posterior insula, a region strongly interconnected with all other vestibular regions (Grüsser et al., 1990; Guldin and Grüsser, 1998). Our data also suggest that signals from the semicircular canals and otolith receptors converge in the insula, as revealed by methods involving different subtypes of vestibular receptors. The insula has also been described as an important area of convergence for self-motion signals including vestibular, optokinetic, proprioceptive and tactile signals (Bottini et al., 2001; Hegemann et al., 2003; Bjornsdotter et al., 2009). In patients with a bilateral vestibular failure, the activation of this region is strongly reduced, suggesting that it usually processes vestibular signals (Bense et al., 2004).

In the parietal operculum we found convergence between CVS and GVS, suggesting that this area also receives afferents from all categories of vestibular receptors. The importance of the parietal operculum in vestibular processing has been stressed by Eickhoff and colleagues (2006b), who combined fMRI and cytoarchitectonic mapping, proposing that the human equivalent of the PIVC is located in OP2. The analysis of the cytoarchitectonic organization of OP2 revealed that this region resembles a koniocortex and thus has the structure of other primary sensory cortices. As pointed out by the authors, there is a strong anatomical analogy between the human OP2 and the monkey PIVC. Indeed, OP2 "is located deep within the Sylvian fissure at the junction of the posterior parietal operculum with the insular/retroinsular region" (Eickhoff et al., 2006b) and therefore strongly resembles the location of the monkey PIVC (Grüsser et al., 1990; 
Guldin and Grüsser, 1998). A recent meta-analysis suggested that the right area OP2 is a core vestibular region because it shows a convergence of methods employing CVS and non-caloric stimulation (Zu Eulenburg et al., 2012). In addition, left and right cold CVS evoked activations overlapping in OP2 (Zu Eulenburg et al., 2012) and functional connectivity analysis demonstrated that OP2 is connected with all other brain areas revealed by this meta-analysis (temporo-parietal, premotor and midcingulate cortex; Zu Eulenburg et al., 2012).

Here, we argue that the retroinsular cortex is another important region for central vestibular processing because it shows a robust convergence between CVS and GVS, CVS and sounds, and GVS and sounds. In addition, only one cluster located in the retroinsular cortex showed an overlap of activations related to all three types of vestibular stimulation. The retroinsular cortex may be a central region for canal-otolith integration, or may be a central region for processing otolith/tilt signals due to the fact that the three main stimulation methods that are available to date all involve otolith/tilt responses (see Fig. 1). The area of maximal overlap between the three stimulation methods was located in the left retroinsular cortex, at the most caudal part of the Sylvian fissure corresponding to the junction between the inferior parietal cortex and the superior temporal cortex. Such activation was located immediately posterior to OP2, which has been shown to extend into the retroinsular cortex, but not to the most caudal part of the Sylvian fissure (Eickhoff et al., 2006a). Thus, the area of maximal convergence revealed by our study is located in the retroinsular cortex, in close vicinity to OP2 (Eickhoff et al., 2006b; Zu Eulenburg et al., 2012), rather than in the posterior insula as could have been expected from previous clinical and neuroimaging studies. We note that the convergence of CVS, GVS, and sound-related activations at the junction between the retroinsular cortex and OP2 is in line with the description of the PIVC in Java monkeys showing that "the main clusters of vestibular neurons were found in the upper bank of the lateral sulcus at the transition of its opercular part into the retroinsular region" (Grüsser et al., 1990) (see Fig. 6). Furthermore, the fact that the region of convergence is located in the retroinsular cortex is consistent with the cytoarchitectonic organization of the Java monkey's PIVC, revealing that most of the vestibularsensitive neurons were recorded within a sub-region called reipt (area retroinsularis pars parietalis) or $\mathrm{Ri}$ (area retroinsularis) and in the transition zones between SII, Ri and Ig (Grüsser et al., 1990). Similar conclusions were recently drawn from anatomical observations in Rhesus monkeys revealing neurons responding to both sinusoidal rotations and translations in the retroinsular cortex, rather than in Ig (Chen et al., 2010; Liu et al., 2011) (see Fig. 6). These latter anatomical and electrophysiological studies thus demonstrated a convergence of signals from the semicircular canals and otoliths in the retroinsular cortex that helped the disambiguation of gravito-inertial forces (Liu et al., 2010). We conclude this paragraph by emphasizing that this meta-analysis provides the first demonstration of a convergence of canal and otolith signals in the retroinsular cortex by merging available neuroimaging data recorded during various stimulating methods.
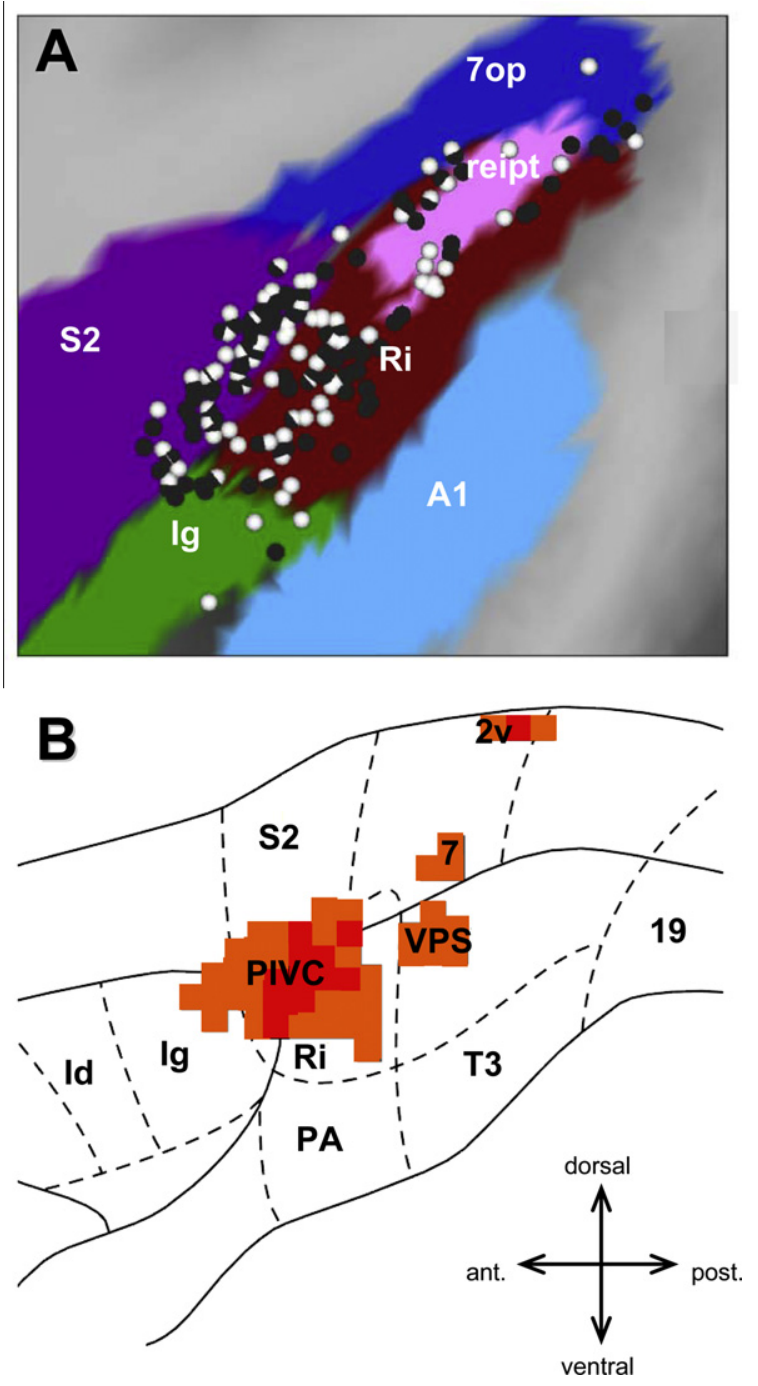

Fig. 6. Localization of the vestibular cortex in the lateral fissure of Old World (rhesus monkey) and New World (squirrel monkey) non-human primates. (A) Localization of vestibular-responsive neurons in the lateral sulcus of a rhesus monkey (Macaca mulatta). Black dots represent recording sites at which vestibular responses were recorded. Adapted from Chen et al. (2010). (B) Localization of the vestibular cortex by a statistical analysis of the cortico-cortical connections in squirrel monkeys (Saimiri sciureus). Adapted from Guldin and Grüsser (1998). 2v, vestibular region in Brodmann area 2; 7op, area 7 operculum; A1, primary auditory cortex; Ig, granular insular cortex; Id, disgranular insular cortex; PA, para-acoustic area; PIVC, parieto-insular vestibular cortex; reipt, area retroinsularis pars parietalis; $\mathrm{Ri}$, retroinsular cortex; $\mathrm{S} 2$, secondary somatosensory cortex; VPS, visual posterior Sylvian area.

\section{Laterality of vestibular projections}

The additional meta-analysis conducted in right-handed participants indicates two main findings concerning the laterality of the vestibular projections:

- The first result is that during the "activation" of one ear, both cerebral hemispheres are activated, thus revealing that vestibular projections are bilateral. Consistent 
with our data, the recent use of Doppler ultrasound combined with GVS revealed that the cerebral blood flow increased in both cerebral hemispheres, indicating bilateral vestibular projections from one peripheral vestibular organ (Schlosser et al., 2008).

- The second result is that the activation in the hemisphere ipsilateral to the "activated" ear is larger (in terms of volume) than the activation in the contralateral hemisphere. This suggests a potential ipsilateral dominance of vestibular projections in right-handed subjects (Fig. 5B and C). In order to interpret correctly our findings, it is important to note that the ALE maps were calculated on the basis of studies simulating either a movement to the right (relative right-ear excitation) or to the left (relative left-ear excitation). Thus, for the calculation of these individual ALE maps, we included studies using different stimulation methods and paradigms (e.g. cold and warm CVS), but with a coherent pattern of behavioral effects evoked by the vestibular stimulation (see Table 2). We believe that, because the vestibular cortex is a motionsensitive cortex, it was appropriate to merge studies based on the behavioral consequence of the vestibular stimulation. Nevertheless, the use of CVS with cold or warm water may have activated different subregions of the insular cortex (Davis et al., 1998), but these activations may not converge sufficiently across studies to be statistically revealed by the meta-analysis.

Although our data are indicative of larger activations in the ipsilateral hemisphere, it is not possible to conclude from the present meta-analysis about the intensity of the vestibular response in the ipsilateral and contralateral vestibular regions. However, a previous study used electroencephalography to measure the amplitude of scalp potentials evoked by direct electrical stimulation of the vestibular nerve in patients undergoing a resection of the vestibular nerve (de Waele et al., 2001). These authors showed that early vestibular-evoked potentials recorded at electrodes located ipsilateral to the stimulated nerve were larger than those recorded contralaterally. Such predominant activation of the ipsilateral cortex has been emphasized by Dieterich and colleagues in a series of studies in healthy and brain-damaged patients (Dieterich et al., 2003, 2005). Interestingly, this pattern of dominant ipsilateral projections does not confirm the knowledge obtained from animal data. Although bilateral projections have been reported in animals, electrophysiological recordings have in general stressed contralateral projections to the cerebral cortex, with stronger vestibular-evoked potentials on the side contralateral to the stimulation (Ödkvist et al., 1974; Ebata et al., 2004). In addition, the laterality of the cortical projections for the vestibular system differs from the strongly lateralized contralateral pathways in the visual and somatosensory systems (Squire et al., 2008). It also differs from the bilateral, although mainly contralateral, neural pathways reported for the auditory system (Squire et al., 2008). More work is necessary, to investigate the laterality of cortical vestibular projections.

\section{Methodological limitations for localizing the vestibular cortex}

The present ALE meta-analysis aims at localizing the regions that are most commonly activated by various methods to stimulate the vestibular receptors. However, the meta-analysis incorporates coordinates of activation from studies employing different methods, experimental paradigms, neuroimaging techniques and number of participants. The meta-analysis is supposed to incorporate this variability and to statistically evaluate the chance that a given voxel shows a convergence of activation between multiple studies. However, the results of any coordinatebased meta-analysis may be influenced by several factors that we detail below.

First, the number of studies and activation foci included in our different meta-analyses is variable (261 foci were analyzed for CVS, 58 foci for GVS and 33 foci for sounds). We acknowledge that this is a limitation of the present meta-analysis and that due to the small number of foci included in the GVS and sounds metaanalyses, the results have to be seen carefully. We note that analyses with small samples have been conducted by others (e.g. Grosbras et al., 2012) and researchers who developed the ALE algorithm indicate that the meta-analysis of sensory functions (as opposed to cognitive processing) require fewer activation foci for the analysis (Laird et al., 2005). Laird et al. (2005) thoroughly discussed the issue of the number of foci included in an ALE meta-analysis. These authors showed that the results of the ALE meta-analysis are indirectly influenced by the number of foci included. However, they indicate that "although the dependency on [the number of foci] causes some difficulty when assessing and making inferences on the results of a meta-analysis of 75 foci and another of 375 foci, it is not necessarily an artifact that invalidates the ALE method itself." Here, the individual meta-analyses were conducted using similar statistical thresholds with $P<0.05$, a similar minimum cluster size of $100 \mathrm{~mm}^{3}$, and importantly identical correction for false discovery rate. Laird et al. (2005) showed that false discovery rate correction is strongly adapted to threshold ALE maps calculated on the basis of small and large samples of activation foci.

The second point is that the studies included in the present meta-analysis employed very different methods to stimulate the vestibular receptors. For example, regarding CVS, which has been the most common technique to stimulate the vestibular system, irrigation of the auditory canal was applied always monaurally, but with different temperatures. Most studies (10/15 contrasts) used irrigation of the ear with cold water (iced water, $0^{\circ}$, $4^{\circ}, 10^{\circ}$ or $20^{\circ}$ ), while few studies (5/15 contrasts) used irrigation with warm water (at $44^{\circ}$ ). Recently, Maes et al. (2007) failed to find a difference in eye movements responses evoked by warm and cold CVS, but these authors indicate that several studies reported a stronger effect of warm than cold CVS. Consequently, the neural responses elicited by the various thermal stimulations may differ in terms of amplitude, because irrigation at $0^{\circ}$ should evoke stronger self-motion perception and larger brain activations than irrigation at $20^{\circ}$ (see Kolev, 2001). 
However, the present ALE meta-analysis used the coordinates of the peaks of activation reported in neuroimaging studies and analyzed their convergence. This approach does not allow to take into account the intensity of the activations reported in the original publications.

A third and important point concerns the contamination of the results of the meta-analysis by non-specific, but nevertheless consistent, sensorimotor components in the original neuroimaging studies. Overlaps between activations evoked by at least two stimulation methods were found in the retroinsular cortex, OP2 and the posterior insula. These regions likely represent important sites for vestibular processing. However, one can question to what extent they may also be involved in non-vestibular and non-specific aspects of vestibular stimulation (for a discussion, see Emri et al., 2003). Indeed, CVS is associated with tactile and thermal stimulation of the external auditory canal, sometimes with nociceptive stimulation, as well as with auditory stimulation. GVS may induce unpleasant, pain and heat sensation under the electrodes attached to the skin. Sound-induced stimulation invariably activates auditory receptors. In addition, CVS and GVS may induce slight feelings of nausea, vertigo, and modify the subject's arousal. Various authors have made attempts to eliminate non-specific co-activations of the tactile, thermal, nociceptive and auditory systems. The nociceptive stimulation induced by GVS at the level of the mastoid processes has been corrected in some studies by analyzing activations induced by the same stimulation applied over other skin regions (Lobel et al., 1998; Bense et al., 2001). The auditory stimulation induced by clicks and short-tone bursts has been corrected by subtracting activations induced by low-intensity clicks or white noise controlling for the loudness of the auditory stimuli (Miyamoto et al., 2007; Schlindwein et al., 2008). Controlling for tactile and thermal effects of CVS has been done, for example, by starting the scanning $10-25 \mathrm{~s}$ after the termination of the irrigation (Bottini et al., 2001; Dieterich et al., 2003). However, despite various attempts to control for unspecific co-activations of the somatosensory systems, it remains difficult to exclude them entirely and this may have partly affected the reported results, and hence the present meta-analysis. Indeed, if a sensory system is non-specifically activated in a large number of studies, it may appear in the results of the ALE meta-analysis, which calculates convergence across studies. Especially, tactile and thermal stimulation of the ear or mastoid processes is common to studies using CVS and GVS (although not to sound-related vestibular activations), and may therefore be apparent in the results of the present meta-analysis. Recent fMRI studies showed that the insular and opercular regions respond to pain and thermal stimulation applied to the hand and foot (Davis et al., 1998; Baumgartner et al., 2010). However, it should be noted that somatosensory representations of the ears are located more dorsally in the somatosensory cortex than the regions found in the present study (Nihashi et al., 2002). In addition, CVS and GVS activate some common regions (retroinsular cortex) with auditory clicks and short-tone bursts, despite the fact that these latter auditory stimulations do not activate tactile and thermal receptors. Another strong argument speaking in favor of a vestibular representation in the retroinsular cortex and insula comes from the observation that CVS applied in patients with vestibular loss induces no or a drastically reduced activity in these regions (Bense et al., 2004). In addition, the statistical comparison of activations induced by CVS in healthy participants versus patients with a vestibular deafferentation (thus controlling for somatosensory co-activations of the CVS) showed a stronger activity in the retroinsular and insular region in the control population (Emri et al., 2003; Bense et al., 2004). New paradigms will have to be developed in the future to better control for the possible thermal and tactile influence of CVS and GVS, and hopefully achieve more selective vestibular stimulation.

\section{Functional and clinical significance}

We believe that the present results may help understand some of the mechanisms underlying the behavioral effects of vestibular stimulations in healthy and neurological populations. CVS and GVS have often been used as methods to investigate the influence of vestibular signals on various cognitive functions in healthy participants (for recent reviews, see: Miller and Ngo, 2007; Utz et al., 2010). The behavioral effects of CVS and GVS are multiple and this can be explained by the wide vestibular projections to the parietal, temporal, frontal and insular cortices reported in the present meta-analysis and in previous neuroimaging studies. Thus, vestibular stimulations have been shown to modulate performance in simple visual-spatial tasks such as line bisection, perception of straight ahead, and visual vertical perception (Utz et al., 2010). Not much is known about the underlying mechanisms. Fink et al. (2003) showed that the influence of GVS on line bisection judgments is related to vestibular interference with the posterior parietal cortex and ventral premotor cortex. More complex spatial functions, such as mental imagery of bodies and objects, are also known to be influenced by CVS (Mast et al., 2006) and GVS (Lenggenhager et al., 2008). Such effects may be explained by the numerous vestibular projections to the parietal cortex and temporo-parietal cortex. Based on these results it has been proposed that part of the vestibular cortex may be engaged in mental imagery of wholebody motion (Blanke et al., 2005). Finally, several studies proposed a vestibular contribution to spatial memory, based on vestibulo-hippocampal interactions. However, such interaction is not corroborated by the results of the present meta-analysis that did not reveal consistent activation of the hippocampus as in previous studies (Vitte et al., 1996; Suzuki et al., 2001).

Interestingly, vestibular stimulations have been used to modulate bodily symptoms in neurological disease. The beneficial influence of CVS has been demonstrated in the case of spatial neglect, hemianesthesia, anosognosia and somatoparaphrenia (Bottini et al., 1995), all of them are deficits concerning the perception, awareness and ownership of the body. Therefore, it was proposed that vestibular signals interfere with the neural bases of body representation and awareness. For example, vestibular stimulation can temporarily suppress disownership 
for body parts in neurological patients suffering from somatoparaphrenia. Interestingly, disownership for body parts has been attributed to damage to the posterior insula (Karnath et al., 2005), and the vestibular representation found in the posterior insula by the present analysis provides a neural basis of the influence of CVS on body part ownership. Another example is the influence of CVS on hemianesthesia. Bottini et al. (2005) have proposed that vestibular-tactile interactions are mediated by the secondary somatosensory cortex, insula, retroinsular cortex, and superior temporal gyrus. Especially, they found that CVS interferes with tactile processing in a region closely overlapping with the retroinsular cortex/OP2 region revealed by the present analysis (they found activations in the right hemisphere: $x=54, y=-32, z=24$; and in the left hemisphere: $x=52, y=-40, z=26$ ). The regions that our analysis proposes to be activated in the posterior Sylvian region could thus be involved in vestibularsomatosensory convergence. Such multisensory convergence in the retroinsular cortex has also been proposed based on electrophysiological results in monkeys: Robinson and Burton (1980) showed that $74 \%$ of retroinsular neurons respond to somatosensory stimuli and Chen et al. (2010) found a high concentration of vestibular-responsive neurons in the retroinsular cortex. Such convergence may also explain the modulation of tactile acuity reported after CVS in healthy participants (Ferre et al., 2011).

Finally, the mapping of the human vestibular cortex is also important to interpret recent findings according to which vestibular processing would be involved in the highest levels of body representation, cognition, and self-consciousness. CVS has been reported to induce symptoms of depersonalization and derealization in healthy participants, and patients with vestibular disorders may experience disorders of the self, including separation of the self from the body (Yen Pik Sang et al., 2006). It has also been proposed that the vestibular cortex may overlap with brain regions involved in processing related to self-location (lonta et al., 2011) and more generally self-processing (Lopez et al., 2008). Such vestibular regions may include the temporo-parietal junction, insula and retroinsular cortex, as revealed in the present metaanalysis.

\section{CONCLUSION}

The present ALE meta-analysis provides the first statistical description and comparison of the brain activations evoked by various types of vestibular stimulation. The results support the view according to which vestibular processing depends on a network of brain regions whose epicenter is located in the Sylvian fissure and surrounding parieto-temporal and retroinsular regions. We believe that the present results will be helpful to constrain future behavioral experiments aiming to manipulate cognitive and sensorimotor functions using CVS and GVS. Beyond informing vestibular research and clinical work the present data are also crucial to better understand the newly described contributions of vestibular cortical signals to internal models of gravity (Indovina et al., 2005), bodily awareness (Bottini et al., 1995) and self-consciousness (lonta et al., 2011).

Acknowledgements-We are very thankful to the Drs. F. Esposito, S. Hegemann, V. Marcelli, M. Pawlowski and P.P. Vidal for kindly providing coordinates of activation or complementary information about their neuroimaging study. We thank Dr. S. Ionta for his help in image processing and Prof. G. Galati for providing access to the software BrainShow. We are thankful to C. Falconer for her comments on the manuscript. This study was supported by the Swiss National Science Foundation (SINERGIA Project "Balancing Self and Body": CRSII1-125135). C. Lopez is supported by the Volkswagenstiftung's European Platform for Life Sciences, Mind Sciences, and the Humanities ("The (Un)bound Body Project. Exploring the constraints of embodiment \& the limits of body representation").

\section{REFERENCES}

Akbarian S, Grüsser OJ, Guldin WO (1992) Thalamic connections of the vestibular cortical fields in the squirrel monkey (Saimiri sciureus). J Comp Neurol 326:423-441.

Albrecht J, Kopietz R, Frasnelli J, Wiesmann M, Hummel $T$, Lundstrom JN (2010) The neuronal correlates of intranasal trigeminal function - an ALE meta-analysis of human functional brain imaging data. Brain Res Rev 62:183-196.

Augustine JR (1996) Circuitry and functional aspects of the insular lobe in primates including humans. Brain Res Brain Res Rev 22:229-244.

Aw ST, Haslwanter T, Fetter M, Dichgans J (2000) Threedimensional spatial characteristics of caloric nystagmus. Exp Brain Res 134:289-294.

Aw SD, Todd MJ, Aw GE, Weber KP, Halmagyi GM (2008) Gentamicin vestibulotoxicity impairs human electrically evoked vestibulo-ocular reflex. Neurology 25:1776-1782.

Baier B, Bense S, Dieterich M (2008) Are signs of ocular tilt reaction in patients with cerebellar lesions mediated by the dentate nucleus? Brain 131:1445-1454.

Baumgartner U, lannetti GD, Zambreanu L, Stoeter P, Treede RD, Tracey I (2010) Multiple somatotopic representations of heat and mechanical pain in the operculo-insular cortex: a high-resolution fMRI study. J Neurophysiol 104:2863-2872.

Bense S, Stephan T, Yousry TA, Brandt T, Dieterich M (2001) Multisensory cortical signal increases and decreases during vestibular galvanic stimulation (fMRI). J Neurophysiol 85:886-899.

Bense S, Deutschländer A, Stephan T, Bartenstein P, Schwaiger M, Brandt T, Dieterich M (2004) Preserved visual-vestibular interaction in patients with bilateral vestibular failure. Neurology 63:122-128.

Berthoz A (1996) How does the cerebral cortex process and utilize vestibular signals? In: Disorders of the vestibular system (Baloh RW, Halmagyi GM, eds), pp 113-125. New York: Oxford University Press.

Berthoz A, Israel I, Georges-Francois P, Grasso R, Tsuzuku T (1995) Spatial memory of body linear displacement: what is being stored? Science 269:95-98.

Bjornsdotter M, Loken L, Olausson H, Vallbo A, Wessberg J (2009) Somatotopic organization of gentle touch processing in the posterior insular cortex. J Neurosci 29:9314-9320.

Blanke O, Perrig S, Thut G, Landis T, Seeck M (2000a) Simple and complex vestibular responses induced by electrical cortical stimulation of the parietal cortex in humans. J Neurol Neurosurg Psychiatry 69:553-556.

Blanke O, Spinelli L, Thut G, Michel CM, Perrig S, Landis T, Seeck M (2000b) Location of the human frontal eye field as defined by electrical cortical stimulation: anatomical, functional and electrophysiological characteristics. Neuroreport 11:1907-1913. 
Blanke O, Ortigue S, Landis T, Seeck M (2002) Stimulating illusory own-body perceptions. Nature 419:269-270.

Blanke O, Mohr C, Michel CM, Pascual-Leone A, Brugger P, Seeck $M$, Landis T, Thut $G$ (2005) Linking out-of-body experience and self processing to mental own-body imagery at the temporoparietal junction. J Neurosci 25:550-557.

Blum PS, Day MJ, Carpenter MB, Gilman S (1979) Thalamic components of the ascending vestibular system. Exp Neurol 64:587-603.

Bottini G, Sterzi R, Paulesu E, Vallar G, Cappa SF, Erminio F, Passingham RE, Frith CD, Frackowiak RS (1994) Identification of the central vestibular projections in man: a positron emission tomography activation study. Exp Brain Res 99:164-169.

Bottini G, Paulesu E, Sterzi R, Warburton E, Wise RJ, Vallar G, Frith CD (1995) Modulation of conscious experience by peripheral sensory stimuli. Nature 376:778-781.

Bottini G, Karnath HO, Vallar G, Sterzi R, Frith CD, Frackowiak RS, Paulesu E (2001) Cerebral representations for egocentric space. Functional-anatomical evidence from caloric vestibular stimulation and neck vibration. Brain 124:1182-1196.

Bottini G, Paulesu E, Gandola M, Loffredo S, Scarpa P, Sterzi R, Santilli I, Defanti CA, Scialfa G, Fazio F, Vallar G (2005) Left caloric vestibular stimulation ameliorates right hemianesthesia. Neurology 65:1278-1283.

Brandt T, Dieterich M (1999) The vestibular cortex. Its locations, functions, and disorders. Ann N Y Acad Sci 871:293-312.

Brandt T, Schautzer F, Hamilton DA, Bruning R, Markowitsch HJ, Kalla R, Darlington C, Smith P, Strupp M (2005) Vestibular loss causes hippocampal atrophy and impaired spatial memory in humans. Brain 128:2732-2741.

Bremmer F, Klam F, Duhamel JR, Ben Hamed S, Graf W (2002) Visual-vestibular interactive responses in the macaque ventral intraparietal area (VIP). Eur J Neurosci 16:1569-1586.

Bucher SF, Dieterich M, Seelos KC, Brandt T (1997) Sensorimotor cerebral activation during optokinetic nystagmus. A functional MRI study. Neurology 49:1370-1377.

Bucher SF, Dieterich M, Wiesmann M, Weiss A, Zink R, Yousry TA, Brandt T (1998) Cerebral functional magnetic resonance imaging of vestibular, auditory, and nociceptive areas during galvanic stimulation. Ann Neurol 44:120-125.

Büttner-Ennever JA (1999) A review of otolith pathways to brainstem and cerebellum. Ann N Y Acad Sci 871:51-64.

Caspers S, Zilles K, Laird AR, Eickhoff SB (2010) ALE meta-analysis of action observation and imitation in the human brain. Neuroimage 50:1148-1167.

Cavanna AE, Trimble MR (2006) The precuneus: a review of its functional anatomy and behavioural correlates. Brain 129:564-583.

Ceballos-Baumann AO, Boecker H, Fogel W, Alesch F, Bartenstein $\mathrm{P}$, Conrad B, Diederich N, von Falkenhayn I, Moringlane JR, Schwaiger M, Tronnier VM (2001) Thalamic stimulation for essential tremor activates motor and deactivates vestibular cortex. Neurology 56:1347-1354.

Chen A, DeAngelis GC, Angelaki DE (2010) Macaque parieto-insular vestibular cortex: responses to self-motion and optic flow. J Neurosci 30:3022-3042.

Corbetta M, Miezin FM, Shulman GL, Petersen SE (1993) A PET study of visuospatial attention. J Neurosci 13:1202-1226.

Craig AD (2009) How do you feel - now? The anterior insula and human awareness. Nat Rev Neurosci 10:59-70.

Crick FC, Koch C (2005) What is the function of the claustrum? Philos Trans R Soc Lond B Biol Sci 360:1271-1279.

Davis KD, Kwan CL, Crawley AP, Mikulis DJ (1998) Functional MRI study of thalamic and cortical activations evoked by cutaneous heat, cold, and tactile stimuli. J Neurophysiol 80:1533-1546.

de Waele C, Baudonnière PM, Lepecq JC, Tran Ba Huy P, Vidal PP (2001) Vestibular projections in the human cortex. Exp Brain Res 141:541-551.

Deutschländer A, Bense S, Stephan T, Schwaiger M, Brandt T, Dieterich M (2002) Sensory system interactions during simultaneous vestibular and visual stimulation in PET. Hum Brain Mapp 16:92-103.

Devinsky O, Morrell MJ, Vogt BA (1995) Contributions of anterior cingulate cortex to behaviour. Brain 118(Pt. 1):279-306.

Dieterich M, Bucher SF, Seelos KC, Brandt T (1998) Horizontal or vertical optokinetic stimulation activates visual motion-sensitive, ocular motor and vestibular cortex areas with right hemispheric dominance. An fMRI study. Brain 121:1479-1495.

Dieterich M, Bense S, Lutz S, Drzezga A, Stephan T, Bartenstein P, Brandt T (2003) Dominance for vestibular cortical function in the non-dominant hemisphere. Cereb Cortex 13:994-1007.

Dieterich M, Bartenstein P, Spiegel S, Bense S, Schwaiger M, Brandt $T$ (2005) Thalamic infarctions cause side-specific suppression of vestibular cortex activations. Brain 128:2052-2067.

Dum RP, Strick PL (1991) The origin of corticospinal projections from the premotor areas in the frontal lobe. J Neurosci 11:667-689.

Ebata S, Sugiuchi Y, Izawa Y, Shinomiya K, Shinoda Y (2004) Vestibular projection to the periarcuate cortex in the monkey. Neurosci Res 49:55-68.

Eickhoff SB, Schleicher A, Zilles K (2006a) The human parietal operculum. I. Cytoarchitectonic mapping of subdivisions. Cereb Cortex 16:254-267.

Eickhoff SB, Weiss PH, Amunts K, Fink GR, Zilles K (2006b) Identifying human parieto-insular vestibular cortex using $\mathrm{fMRI}$ and cytoarchitectonic mapping. Hum Brain Mapp 27:611-621.

Eickhoff SB, Laird AR, Grefkes C, Wang LE, Zilles K, Fox PT (2009) Coordinate-based activation likelihood estimation meta-analysis of neuroimaging data: a random-effects approach based on empirical estimates of spatial uncertainty. Hum Brain Mapp 30:2907-2926

Emri M, Kisely M, Lengyel Z, Balkay L, Marian T, Miko L, Berenyi E, Sziklai I, Tron L, Toth A (2003) Cortical projection of peripheral vestibular signaling. J Neurophysiol 89:2639-2646.

Fasold $\mathrm{O}$, von Brevern $\mathrm{M}$, Kuhberg $\mathrm{M}$, Ploner $\mathrm{CJ}$, Villringer $\mathrm{A}$, Lempert T, Wenzel R (2002) Human vestibular cortex as identified with caloric stimulation in functional magnetic resonance imaging. Neuroimage 17:1384-1393.

Faugier-Grimaud S, Ventre J (1989) Anatomic connections of inferior parietal cortex (area 7) with subcortical structures related to vestibulo-ocular function in a monkey (Macaca fascicularis). J Comp Neurol 280:1-14.

Fernandez-Miranda JC, Rhoton Jr AL, Kakizawa Y, Choi C, AlvarezLinera J (2008) The claustrum and its projection system in the human brain: a microsurgical and tractographic anatomical study. J Neurosurg 108:764-774.

Ferre ER, Sedda A, Gandola M, Bottini G (2011) How the vestibular system modulates tactile perception in normal subjects: a behavioural and physiological study. Exp Brain Res 208:29-38.

Fink GR, Marshall JC, Weiss PH, Stephan T, Grefkes C, Shah NJ, Zilles K, Dieterich M (2003) Performing allocentric visuospatial judgments with induced distortion of the egocentric reference frame: an fMRI study with clinical implications. Neuroimage 20:1505-1517.

Fitzpatrick RC, Day BL (2004) Probing the human vestibular system with galvanic stimulation. J Appl Physiol 96:2301-2316.

Fukushima J, Akao T, Takeichi N, Kurkin S, Kaneko CR, Fukushima K (2004) Pursuit-related neurons in the supplementary eye fields: discharge during pursuit and passive whole body rotation. J Neurophysiol 91:2809-2825.

Galati G, Committeri G, Spitoni G, Aprile T, Di Russo F, Pizzamiglio L (2008) A selective representation of the meaning of actions in the auditory mirror system. Neuroimage 40:1274-1286.

Ghaem O, Mellet E, Crivello F, Tzourio N, Mazoyer B, Berthoz A, Denis M (1997) Mental navigation along memorized routes activates the hippocampus, precuneus, and insula. Neuroreport 8:739-744.

Grosbras MH, Beaton S, Eickhoff S (2012) Brain regions involved in human movement perception: a quantitative voxel-based metaanalysis. Hum Brain Mapp 33:431-454. 
Grüsser OJ, Pause M, Schreiter U (1990) Localization and responses of neurones in the parieto-insular vestibular cortex of awake monkeys (Macaca fascicularis). J Physiol 430:537-557.

Grüsser OJ, Guldin WO, Mirring S, Salah-Eldin A (1994) Comparative physiological and anatomical studies of the primate vestibular cortex. In: Structural and functional organization of the neocortex (Albowitz B, et al., eds), pp 358371. Berlin: Springer-Verlag.

Gu Y, DeAngelis GC, Angelaki DE (2007) A functional link between area MSTd and heading perception based on vestibular signals. Nat Neurosci 10:1038-1047.

Guldin WO, Grüsser OJ (1998) Is there a vestibular cortex? Trends Neurosci 21:254-259.

Hadjikhani N, Roland PE (1998) Cross-modal transfer of information between the tactile and the visual representations in the human brain: a positron emission tomographic study. J Neurosci 18:1072-1084.

Halmagyi GM, Curthoys IS, Colebatch JG, Aw ST (2005) Vestibular responses to sound. Ann N Y Acad Sci 1039:54-67.

Hegemann S, Pawlowski M, Huonker R, Haueisen J, Fitzek C, Fetter M (2003) Magnetoencephalography during optokinetic and vestibular activation of the posterior insula. Ann N Y Acad Sci 1004:457-464.

Heydrich L, Lopez C, Seeck M, Blanke O (2011) Partial and full ownbody illusions of epileptic origin in a child with right temporoparietal epilepsy. Epilepsy Behav 20:583-586.

Indovina I, Maffei V, Bosco G, Zago M, Macaluso E, Lacquaniti F (2005) Representation of visual gravitational motion in the human vestibular cortex. Science 308:416-419.

Ionta S, Heydrich L, Lenggenhager B, Mouthon M, Fornari E, Chapuis D, Gassert R, Blanke O (2011) Multisensory mechanisms in temporo-parietal cortex support self-location and first-person perspective. Neuron 70:363-374.

Isnard J, Guenot M, Sindou M, Mauguiere F (2004) Clinical manifestations of insular lobe seizures: a stereoelectroencephalographic study. Epilepsia 45:1079-1090.

Jahn K, Deutschländer A, Stephan T, Strupp M, Wiesmann M, Brandt $T$ (2004) Brain activation patterns during imagined stance and locomotion in functional magnetic resonance imaging. Neuroimage 22:1722-1731.

Janzen J, Schlindwein P, Bense S, Bauermann T, Vucurevic G, Stoeter P, Dieterich M (2008) Neural correlates of hemispheric dominance and ipsilaterality within the vestibular system. Neuroimage 42:1508-1518.

Jones EG The thalamus. New York and London: Plenum Press; 1985.

Kahane P, Hoffmann D, Minotti L, Berthoz A (2003) Reappraisal of the human vestibular cortex by cortical electrical stimulation study. Ann Neurol 54:615-624.

Karnath HO, Baier B, Nagele T (2005) Awareness of the functioning of one's own limbs mediated by the insular cortex? J Neurosci 25:7134-7138.

Kolev OI (2001) The directions of nystagmus and apparent selfmotion evoked by caloric tests and angular acceleration. J Vestib Res 11:349-355.

Koski L, Paus T (2000) Functional connectivity of the anterior cingulate cortex within the human frontal lobe: a brain-mapping meta-analysis. Exp Brain Res 133:55-65.

Kotchabhakdi N, Rinvik E, Walberg F, Yingchareon K (1980) The vestibulothalamic projections in the cat studied by retrograde axonal transport of horseradish peroxidase. Exp Brain Res 40:405-418.

Kovacs G, Raabe M, Greenlee MW (2008) Neural correlates of visually induced self-motion illusion in depth. Cereb Cortex 18:1779-1787.

Kurth F, Eickhoff SB, Schleicher A, Hoemke L, Zilles K, Amunts K (2010a) Cytoarchitecture and probabilistic maps of the human posterior insular cortex. Cereb Cortex 20:1448-1461.

Kurth F, Zilles K, Fox PT, Laird AR, Eickhoff SB (2010b) A link between the systems: functional differentiation and integration within the human insula revealed by meta-analysis. Brain Struct Funct 214:519-534.
Laird AR, Fox PM, Price CJ, Glahn DC, Uecker AM, Lancaster JL, Turkeltaub PE, Kochunov P, Fox PT (2005) ALE meta-analysis: controlling the false discovery rate and performing statistical contrasts. Hum Brain Mapp 25:155-164.

Laird AR, Eickhoff SB, Kurth F, Fox PM, Uecker AM, Turner JA, Robinson JL, Lancaster JL, Fox PT (2009a) ALE meta-analysis workflows via the brainmap database: progress towards a probabilistic functional brain atlas. Front Neuroinformatics 3:23.

Laird AR, Lancaster JL, Fox PT (2009b) Lost in localization? The focus is meta-analysis. Neuroimage 48:18-20.

Lancaster JL, Tordesillas-Gutierrez D, Martinez M, Salinas F, Evans A, Zilles K, Mazziotta JC, Fox PT (2007) Bias between MNI and Talairach coordinates analyzed using the ICBM-152 brain template. Hum Brain Mapp 28:1194-1205.

Lenggenhager B, Lopez C, Blanke O (2008) Influence of galvanic vestibular stimulation on egocentric and object-based mental transformations. Exp Brain Res 184:211-221.

Liedgren SR, Schwarz DW (1976) Vestibular evoked potentials in thalamus and basal ganglia of the squirrel monkey (Saimiri sciureus). Acta Otolaryngol 81:73-82.

Liu S, Yakusheva T, Deangelis GC, Angelaki DE (2010) Direction discrimination thresholds of vestibular and cerebellar nuclei neurons. J Neurosci 30:439-448.

Liu S, Dickman JD, Angelaki DE (2011) Response dynamics and tilt versus translation discrimination in parietoinsular vestibular cortex. Cereb Cortex 21:563-573.

Lobel E, Kleine JF, Le Bihan D, Leroy-Willig A, Berthoz A (1998) Functional MRI of galvanic vestibular stimulation. J Neurophysiol 80:2699-2709.

Lopez C, Blanke O (2011) The thalamocortical vestibular system in animals and humans. Brain Res Rev 67:119-146.

Lopez C, Lacour M, Ahmadi AE, Magnan J, Borel L (2007) Changes of visual vertical perception: a long-term sign of unilateral and bilateral vestibular loss. Neuropsychologia 45:2025-2037.

Lopez C, Halje P, Blanke O (2008) Body ownership and embodiment: vestibular and multisensory mechanisms. Neurophysiol Clin 38:149-161.

Lopez C, Bachofner C, Mercier M, Blanke O (2009) Gravity and observer's body orientation influence the visual perception of human body postures. J Vis 9(1):1-14.

Maes L, Dhooge I, De Vel E, D'Haenens W, Bockstael A, Vinck BM (2007) Water irrigation versus air insufflation: a comparison of two caloric test protocols. Int J Audiol 46:263-269.

Marcelli V, Esposito F, Aragri A, Furia T, Riccardi P, Tosetti M, Biagi L, Marciano E, Di Salle F (2009) Spatio-temporal pattern of vestibular information processing after brief caloric stimulation. Eur J Radiol 70:312-316.

Marlinski V, McCrea RA (2008) Activity of ventroposterior thalamus neurons during rotation and translation in the horizontal plane in the alert squirrel monkey. J Neurophysiol 99:2533-2545.

Mast FW, Merfeld DM, Kosslyn SM (2006) Visual mental imagery during caloric vestibular stimulation. Neuropsychologia 44:101-109.

Meng H, May PJ, Dickman JD, Angelaki DE (2007) Vestibular signals in primate thalamus: properties and origins. J Neurosci 27:13590-13602.

Merfeld DM, Park S, Gianna-Poulin C, Black FO (2005) Vestibular perception and action employ qualitatively different mechanisms. II. VOR and perceptual responses during combined tilt\&translation. J Neurophysiol 94:199-205.

Miller SM, Ngo TT (2007) Studies of caloric vestibular stimulation: implications for cognitive neurosciences, the clinical neurosciences and neurophilosophy. Acta Neuropsychiatrica 19:183-203.

Miyamoto T, Fukushima K, Takada T, de Waele C, Vidal PP (2007) Saccular stimulation of the human cortex: a functional magnetic resonance imaging study. Neurosci Lett 423:68-72.

Naito Y, Tateya I, Hirano S, Inoue M, Funabiki K, Toyoda H, Ueno M, Ishizu K, Nagahama Y, Fukuyama H, Ito J (2003) Cortical correlates of vestibulo-ocular reflex modulation: a PET study. Brain 126:1562-1578. 
Nguyen DK, Nguyen DB, Malak R, Leroux JM, Carmant L, SaintHilaire JM, Giard N, Cossette P, Bouthillier A (2009) Revisiting the role of the insula in refractory partial epilepsy. Epilepsia 50:510-520.

Nihashi T, Kakigi R, Okada T, Sadato N, Kashikura K, Kajita Y, Yoshida J (2002) Functional magnetic resonance imaging evidence for a representation of the ear in human primary somatosensory cortex: comparison with magnetoencephalography study. Neuroimage 2002:17.

Ödkvist LM, Schwarz DWF, Fredrickson JM, Hassler R (1974) Projection of the vestibular nerve to the area 3a arm field in the squirrel monkey (Saimiri sciureus). Exp Brain Res 21:97-105.

O'Mara SM, Rolls ET, Berthoz A, Kesner RP (1994) Neurons responding to whole-body motion in the primate hippocampus. J Neurosci 14:6511-6523.

Paus T, Petrides M, Evans AC, Meyer E (1993) Role of the human anterior cingulate cortex in the control of oculomotor, manual, and speech responses: a positron emission tomography study. J Neurophysiol 70:453-469.

Paus T, Koski L, Caramanos Z, Westbury C (1998) Regional differences in the effects of task difficulty and motor output on blood flow response in the human anterior cingulate cortex: a review of 107 PET activation studies. Neuroreport 9:R37-R47.

Penfield W (1957) Vestibular sensation and the cerebral cortex. Ann Otol Rhinol Laryngol 66:691-698.

Penfield W, Kristiansen K Epileptic seizure patterns. Ilinois: Springfield; 1951.

Percheron G, Francois C, Talbi B, Yelnik J, Fenelon G (1996) The primate motor thalamus. Brain Res Brain Res Rev 22:93-181.

Petacchi A, Laird AR, Fox PT, Bower JM (2005) Cerebellum and auditory function: an ALE meta-analysis of functional neuroimaging studies. Hum Brain Mapp 25:118-128.

Peterka RJ, Gianna-Poulin CC, Zupan LH, Merfeld D (2004) Origin of orientation-dependent asymmetries in vestibulo-ocular reflexes evoked by caloric stimulation. J Neurophysiol 92:2333-2345.

Robinson CJ, Burton H (1980) Somatic submodality distribution within the second somatosensory (SII), 7b, retroinsular, postauditory, and granular insular cortical areas of $M$. fascicularis. J Comp Neurol 192:93-108.

Salimi-Khorshidi G, Smith SM, Keltner JR, Wager TD, Nichols TE (2009) Meta-analysis of neuroimaging data: a comparison of image-based and coordinate-based pooling of studies. Neuroimage 45:810-823.

Schlindwein $P$, Mueller M, Bauermann $T$, Brandt $T$, Stoeter $P$, Dieterich M (2008) Cortical representation of saccular vestibular stimulation: VEMPs in fMRI. Neuroimage 39:19-31.

Schlosser HG, Guldin W, Fritzsche D, Clarke AH (2008) Transcranial Doppler ultrasound during galvanic labyrinth polarization depicts central vestibular processing, demonstrating bilateral vestibular projection. Eur J Neurosci 28:372-378.

Schmahmann JD, Doyon J, McDonald D, Holmes C, Lavoie K, Hurwitz AS, Kabani N, Toga A, Evans A, Petrides M (1999) Three-dimensional MRI atlas of the human cerebellum in proportional stereotaxic space. Neuroimage 10:233-260.
Schwarz DWF, Fredrickson JM (1971) Rhesus monkey vestibular cortex: a bimodal primary projection field. Science 172:280-281.

Sherman SM, Guillery RW (2002) The role of the thalamus in the flow of information to the cortex. Philos Trans R Soc Lond B Biol Sci 357:1695-1708.

Smith BH (1960) Vestibular disturbances in epilepsy. Neurology 10:465-469.

Squire LR, Bloom FE, McDonnell SK, Roberts JL, Spitzer NC, Zigmond MJ Fundamental neuroscience. Amsterdam: Academic Press; 2008.

Stephan T, Deutschländer A, Nolte A, Schneider E, Wiesmann M, Brandt T, Dieterich M (2005) Functional MRI of galvanic vestibular stimulation with alternating currents at different frequencies. Neuroimage 26:721-732.

Stoodley CJ, Schmahmann JD (2009) Functional topography in the human cerebellum: a meta-analysis of neuroimaging studies. Neuroimage 44:489-501.

Suzuki M, Kitano H, Ito R, Kitanishi T, Yazawa Y, Ogawa T, Shiino A, Kitajima K (2001) Cortical and subcortical vestibular response to caloric stimulation detected by functional magnetic resonance imaging. Brain Res Cogn Brain Res 12:441-449.

Talairach J, Tournoux P Co-planar stereotaxic atlas of the human brain. New York: Thieme; 1988.

Turkeltaub PE, Eden GF, Jones KM, Zeffiro TA (2002) Meta-analysis of the functional neuroanatomy of single-word reading: method and validation. Neuroimage 16:765-780.

Utz KS, Dimova V, Oppenlander K, Kerkhoff G (2010) Electrified minds: transcranial direct current stimulation (tDCS) and Galvanic Vestibular Stimulation (GVS) as methods of non-invasive brain stimulation in neuropsychology - A review of current data and future implications. Neuropsychologia 48:2789-2810.

Van Essen DC (2005) A Population-Average, Landmark- and Surface-based (PALS) atlas of human cerebral cortex. Neuroimage 28:635-662.

Vitte E, Derosier C, Caritu Y, Berthoz A, Hasboun D, Soulie D (1996) Activation of the hippocampal formation by vestibular stimulation: a functional magnetic resonance imaging study. Exp Brain Res 112:523-526.

Wiest G, Zimprich F, Prayer D, Czech T, Serles W, Baumgartner C (2004) Vestibular processing in human paramedian precuneus as shown by electrical cortical stimulation. Neurology 62: 473-475.

Xu Y, Simpson I, Tang X, Zhou W (2009) Acoustic clicks activate both the canal and otolith vestibulo-ocular reflex pathways in behaving monkeys. J Assoc Res Otolaryngol 10:569-577.

Yen Pik Sang F, Jauregui-Renaud K, Green DA, Bronstein AM, Gresty MA (2006) Depersonalisation/derealisation symptoms in vestibular disease. J Neurol Neurosurg Psychiatry 77:760-766.

Zhu H, Tang X, Wei W, Mustain W, Xu Y, Zhou W (2011) Clickevoked responses in vestibular afferents in rats. J Neurophysiol 106:754-763.

Zu Eulenburg P, Caspers S, Roski C, Eickhoff SB (2012) Metaanalytical definition and functional connectivity of the human vestibular cortex. Neuroimage 60(1):162-169. 